\title{
O que se Aprende sobre Pêndulo Simples em Atividades Investigativas nos Laboratórios Material e Computacional?
}

\section{What is Actually learned about Simple Pendulum with Inquiry-Based Approach Activities in Material and Computational Laboratories?}

\author{
Silvia Carla Cerqueira Porto Brasil \\ Amanda Amantes Brasil \\ Dielson Pereira Hohenfeld ${ }^{(1)}$ Brasil
}

Relatamos um estudo da aprendizagem de estudantes do ensino médio sobre o conteúdo de Pêndulo Simples quando submetidos a uma intervenção com atividade investigativa em dois tipos de laboratório: computacional e material. A aprendizagem foi avaliada a partir do ganho no entendimento explicitado em dois testes de conhecimento, aplicados a amostras que foram pareadas em relação ao tipo de laboratório. Avaliamos também o tipo de conhecimento que mais evoluiu, tendo-se como parâmetro o caráter conceitual ou procedimental dos itens respondidos. Para efeito de comparação da aprendizagem nos dois tipos de laboratório, utilizamos a proficiência dos sujeitos obtida pela modelagem Rasch, e para comparar a aprendizagem nos domínios conceitual e procedimental utilizamos os índices de dificuldade dos itens obtidos pela mesma modelagem. Nossos resultados indicam que houve maior aprendizagem, em termos de conhecimento formal, no laboratório em ambiente computacional, tendo como parâmetro o conteúdo de Pêndulo Simples, o contexto de aplicação da intervenção e os objetos de aprendizagem que utilizamos. Em termos de domínio de conhecimento, os aspectos procedimentais evoluíram mais, indicando que a atividade investigativa conduzida contemplou em maior escala o entendimento em termos de manipulação dos conceitos para solucionar problemas, o que é razoável se considerarmos o caráter desse tipo de abordagem. Interpretamos os resultados como apontamentos para pensarmos na adequação das estratégias de ensino que utilizamos: é preciso ter clareza do que cada tipo de método proporciona em termos de aprendizagem e suas limitações, para que metodologias de ensino mais eficazes possam ser melhor delineadas e conduzidas.

Palavras-chave: Aprendizagem; Atividade investigativa; Laboratório computacional; Laboratório material; Análise quantitativa.

In this research, we report how high school students learn the Simple Pendulum when subjected to an inquiry-based activity in two types of laboratory: computational and material. Learning was assessed from the gain in understanding described in two 
knowledge tests, applied to samples that were paired in relation to the type of laboratory. We also evaluated what kind of knowledge showed the most progress, regarding the conceptual or procedural nature of the items answered. To compare learning in both types of laboratory, we used the students' proficiency on tests obtained through Rasch Model, and to compare learning in the conceptual and procedural domains, we used the item difficulty indexes from the same Model. Our findings indicated more learning, in terms of formal knowledge, in the computational environment, concerning the content taught (Simple Pendulum), the context of inquiry-based application, and the instruments we used in both virtual and material laboratories. In terms of knowledge domain, the procedural aspects developed the most, indicating that the inquiry-based approach has greatly improved the understanding in terms of manipulating concepts for problem solving, which is reasonable considering the nature of the activity. We interpret the results as an indication that it is necessary to think about educational strategies in order to improve its design to accomplish teaching goals. That is, we need better understanding on what each type of method provides in terms of learning as well as their limitations, so that more effective teaching methodologies can be developed and applied.

Keywords: Learning; Inquiry-based approach; Computational laboratory; Material laboratory; Quantitative analysis.

\section{Introdução}

O laboratório de Física é um ambiente de intercâmbio e interações e, com o passar do tempo, tem sofrido mudanças de diferentes naturezas, o que acaba por propiciar a diversificação de métodos e estratégias de ensino para atender a diferentes objetivos de aprendizagem. Entretanto, ao mesmo tempo em que se apresenta como um espaço em potencial para um ensino plural e mais efetivo em termos de desenvolvimento de habilidades, o laboratório apresenta desafios no que se refere à consolidação de estratégias com objetivos de aprendizagem específicos, uma vez que ele pode ser utilizado como instrumento para desenvolver conhecimentos diversos (criticidade, habilidades técnicas, compreensão do método científico, dentre outras). Nesse sentido, estudos sobre o que é aprendido ou desenvolvido nos mais diversos ambientes de laboratório, assim como na aplicação das diferentes abordagens metodológicas, são essenciais para compreender quais estratégias são mais adequadas a cada objetivo de aprendizagem.

O laboratório como recurso didático tem sido considerado como desejável, tanto por pesquisadores como por docentes, e alguns dos argumentos apontados é que tal recurso favorece i) a interação (pela realização de atividades em grupo); ii) o desenvolvimento de conhecimento técnico (através do manuseio de materiais) e do método científico (pela mobilização de ações que levam à observação e sistematização de dados); iii) o entendimento de fenômenos naturais; iv) o desenvolvimento de raciocínio lógico científico (através da discussão sobre modelos físicos de maneira 
problematizadora) (Alves Filho, 2000; Hohenfeld, 2013). Apesar de não termos resultados empíricos suficientes que nos permitam fazer uma comparação fidedigna da eficácia da abordagem experimental no laboratório didático em relação a outros tipos de abordagem, é praticamente um consenso na área de ensino que situações dessa natureza propiciam uma aprendizagem mais ampla sobre os fenômenos científicos (Araujo, \& Abib, 2003; Giordan, 1999; Oliveira, 2010; Pereira, \& Moreira, 2017; Snetinová, Kácovský, \& Machalická, 2018; Tamir, 1991).

Um dos desafios para a utilização do laboratório em termos de práticas experimentais é a falta de espaço físico e de recursos, tanto material, como de pessoal e também didático. Materiais para experimentos demandam constante manutenção técnica, espaço de armazenamento e planejamento em termos de roteiros e atividades, recursos muitas vezes escassos nas escolas. Contudo, a concepção sobre laboratório didático pode e deve extrapolar à visão de um ambiente totalmente estruturado, específico para realização de atividades para comprovação teórica. Borges (2002) já argumentava que não há uma dependência direta entre a aula experimental e o espaço físico, ou seja, a atividade pode ser realizada na própria sala de aula, que se torna, nesse caso, um laboratório didático. $\mathrm{O}$ interesse principal, nessa perspectiva, é que o pensamento reflexivo do estudante seja despertado por meio da curiosidade de observar o fenômeno, refletir sobre ele e desenvolver seu pensamento no processo de construção do próprio conhecimento (Millar, 2010).

Outra opção para atender à perspectiva de que o laboratório didático pode ser consolidado em diferentes ambientes e demandar outros tipos de recursos que não necessitam de manutenção física, é a utilização de simulações computacionais (Lima, \& Takahashi, 2013). Entretanto, a utilização desse recurso tem suas limitações, pois os objetos não são manipulados como em uma situação material, e isso requer interação com outra interface e objetos de aprendizagem. Portanto, é relevante estabelecer os limites e potencialidades desse recurso, assim como verificar em que medida ele atende às expectativas de ensino e aprendizagem de conteúdos científicos (Vasconcelos, Carvalho, Romeu, \& Neto, 2005).

Um dos aspectos que destacamos nesse trabalho é a oportunidade de confrontar modelos computacionais com os materiais, uma vez que os modelos desempenham um papel fundamental na ciência e no ensino, atuando como mediadores entre realidade e teoria (Pedrajas, 2017). As simulações computacionais possibilitam a representação de diferentes aspectos dos modelos científicos. Segundo Lévy (1993) os cientistas de todas as áreas recorrem cada vez mais a simulações computacionais para estudar fenômenos insensíveis à experiência, tais como: o nascimento do universo, evolução biológica ou demográfica, ou simplesmente para avaliar de maneira menos custosa o interesse de novos modelos, mesmo quando a experimentação é possível. Assim, no contexto educacional, podemos utilizar essa reflexão com a intencionalidade de confronto entre o modelo da simulação computacional e o empírico material, uma vez que o laboratório material lida com instrumentos empíricos táteis enquanto os computacionais estão mais 
ligados no campo visual, imagético da virtualização.

Seja em qual for o ambiente, computacional ou material, o laboratório didático requer planejamento direcionado ao seu objetivo de ensino. Um desses objetivos deve se concentrar em favorecer o desenvolvimento de reflexões, além das interações entre os sujeitos (Almeida, \& Sasseron, 2013). Sobre esse aspecto, Muller, Araujo, Veit e Schell, (2017) e Suart e Marcondes (2009) apontam para a necessidade de o professor usar metodologias que incitem a participação ativa dos estudantes, inserindo, por exemplo, estratégias que utilizem atividades mais desafiadoras.

Muitos estudos têm apontado críticas às atividades do laboratório didático cujo objetivo principal é levar os estudantes a simplesmente manipular objetos e/ou observar fenômenos físicos para, posteriormente, realizar uma reprodução empírica do que é estudado em teoria (Almeida, \& Sasseron, 2013; Carvalho, 2013; Suart, \& Marcondes, 2009). Quando utilizadas, tais atividades têm como foco fazer com que os estudantes comprovem resultados já conhecidos e leiam explicações previamente construídas, contribuindo pouco para um entendimento mais profundo sobre os aspectos fenomenológicos da atividade (Bellucco, \& Carvalho, 2014; Borges, 2002; Capecchi, \& Carvalho, 2000; Carvalho, 2004; Jiménez, \& Alexandre, 2005; Sasseron, \& Carvalho, 2011; Suart, \& Marcondes, 2009).

Uma alternativa apontada é a inserção de uma abordagem mais investigativa nas atividades experimentais. Atividades com essa natureza, ao contrário de atividades experimentais estruturadas para comprovação teórica, podem ser utilizadas no laboratório didático para atender à expectativa de interação e desenvolvimento de um pensamento mais reflexivo, uma vez que compreendem situações desafiadoras a serem solucionadas. Contudo, é necessário ter maior clareza sobre o que esse tipo de estratégia proporciona em termos de elementos de aprendizagem. Nesse sentido, o foco do presente estudo é investigar a aprendizagem, em termos do ganho no entendimento formal, sobre o conteúdo de Pêndulo Simples em dois tipos de laboratório, computacional e material, a partir de uma abordagem investigativa. Buscamos responder às perguntas:

1- Há diferença de aprendizagem no laboratório material e computacional?

2- Qual o tipo de entendimento (Conceitual ou Procedimental) é mais favorecido na atividade investigativa?

\section{Aprendizagem e Atividades Experimentais Investigativas no Laboratório Didático}

Uma atividade experimental quando bem planejada, sem levar em conta o tipo de laboratório em que ela é aplicada, leva o estudante a refletir e a construir seu conhecimento a partir de suas próprias ações. Nesse sentido, Carmo (2012) e Medeiros e Medeiros (2002) destacam algumas vantagens do uso de atividades experimentais: i) facilita a comunicação entre professor e estudante; ii) dá margem a maiores questionamentos e retorno das dúvidas; iii) otimiza às ações referentes à manipulação de materiais e dados; iv) permite testar, gerar e comprovar hipóteses; v) propicia a aproximação dos 
estudantes ao método científico; vi) potencializa o papel do laboratório didático no ensino; vii) promove o aprimoramento de habilidades e viii) facilita o desenvolvimento de uma visão crítica.

Uma potencial estratégia para atender boa parte dos quesitos apontados por esses autores é a atividade investigativa. Nesse tipo de abordagem uma situaçãoproblema é apresentada, e sua solução depende das ações e reflexões dos estudantes (Zômpero, Passos, \& Carvalho, 2012). Algumas pesquisas apontam que atividades dessa natureza promovem o desenvolvimento de habilidades conceituais e procedimentais nos estudantes (Bellucco, \& Carvalho, 2014; Ferreira, 2009). Essa orientação se dá em função da crença de que, ao elaborar estratégias e planos de ação para resolver situaçõesproblema, a aprendizagem do conteúdo se torna mais eficaz. Atividades desse tipo não apresentam procedimentos sequenciados para comprovação teórica, mas sim desafios que compreendem a coleta de dados e informações buscando soluções razoáveis (Gomes, Borges, \& Justi, 2008). A aplicação de uma atividade de natureza investigativa pode solicitar leitura e interpretação de textos, uso de laboratórios didáticos, demonstrações de situações-problema e questionamentos de modo geral. Ela demanda do estudante um pensamento reflexivo em busca de uma teoria de base que respalde os resultados encontrados, podendo utilizar a matemática como suporte quando um tratamento analítico é necessário (Carmo, 2012).

Acreditamos que atividades investigativas experimentais veiculadas nos laboratórios didáticos sejam promissoras para otimizar a aprendizagem dos estudantes sobre conteúdos que demandam altos níveis de abstração, como é o caso de muitos conceitos e fenômenos da Física. Contudo, há de avaliar que tipo de aprendizagem essa estratégia favorece e em qual laboratório (computacional ou material) ela é mais efetiva.

Uma maneira de investigar essa questão é considerar que, dentre os diversos parâmetros que compõem a aprendizagem, um deles é seu caráter processual, que compreende a mudança de traços ao longo do tempo (Wright, 1998). Se considerarmos o entendimento sobre um conceito abordado em uma atividade investigativa como um traço, avaliamos a aprendizagem a partir da mudança desse entendimento. Isso vale também para o tipo de laboratório: tomando como parâmetro de aprendizagem a mudança do entendimento, avaliamos em que medida os laboratórios computacional e material propiciam a aprendizagem através das comparações do quanto o entendimento muda em um e em outro ambiente. O entendimento, nesses termos, pode ser de caráter procedimental ou conceitual. Nesse sentido, é adequado estabelecermos uma "métrica" para compararmos a aprendizagem, seja em relação ao entendimento procedimental, conceitual ou outro tipo de conhecimento ou habilidade. Tal "métrica" deve englobar uma perspectiva qualitativa, na medida em que devemos "qualificar" o que seria um entendimento maior ou mais articulado do que outro, e uma perspectiva quantitativa, que permita comparar as mudanças em termos do "quanto" um laboratório (computacional ou material) favoreceu.

Para construirmos a métrica que nos permitiu estudar a aprendizagem dos 
estudantes em atividades experimentais investigativas nos laboratórios computacional e material, consideramos, na perspectiva qualitativa, a aprendizagem como um processo em que ocorre o aumento da qualidade/complexidade do nível de entendimento procedimental e/ou conceitual do sujeito no decorrer do tempo. Dessa forma, investigamos o processo a partir do estudo da evolução dos níveis de entendimento, identificados por uma métrica qualitativa baseada na Teoria de Habilidades Dinâmicas (Fischer, 1980).

A Teoria de Habilidades Dinâmicas (Fischer, 1980) é pautada em pressupostos piagetianos, mas se diferencia em alguns de seus elementos no intuito de melhor explicar o desenvolvimento dos sujeitos. Ela reconhece o meio externo como importante preditor no processo, assim como adota a hierarquia de estágios como dependente do domínio de conhecimento, e não como uma perspectiva geral de desenvolvimento. Além disso, Fischer (1980) descreve o caminho de desenvolvimento como associado a mudanças observáveis no comportamento das pessoas (Fischer, 1980, 2006), o que remete a habilidades específicas que emergem, se transformam e se tornam cada vez mais complexas. Nessa perspectiva teórica, podemos entender como aprendizagem no laboratório didático a evolução das habilidades específicas, dimensionadas pela complexidade do entendimento dos estudantes em termos procedimentais e conceituais.

Como é uma teoria pautada em princípios piagetianos, são estabelecidas camadas de desenvolvimento semelhantes aos estágios de Piaget (1976), mas que podem ser interpretadas não no sentido geral de desenvolvimento, mas como uma estrutura para interpretar a evolução de habilidades em domínios específicos de conhecimento. Há uma sequência recursiva em que ocorrem mudanças quantitativas do repertório (aumento de elementos mobilizados e de relações estabelecidas) e mudança qualitativa (diferenciação da habilidade), demarcando a mudança de níveis de complexidade no primeiro caso e mudança de camada no segundo. A Figura 1 representa um exemplo de caminho de evolução de uma habilidade ou entendimento.

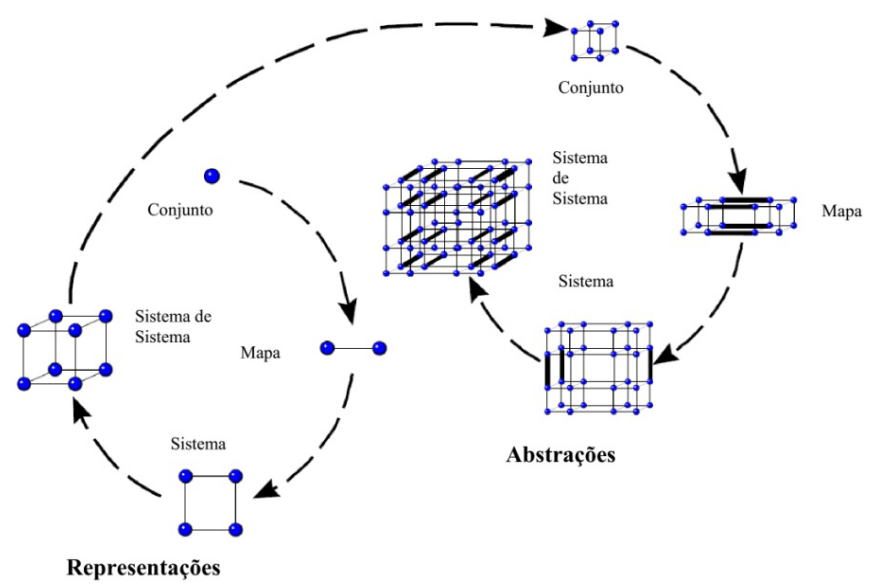

Figura 1. Esquema geral do desenvolvimento em relação aos níveis em meio às camadas Fonte: Fisher, 2008. 
Os elementos ou conjuntos (sets) correspondem ao repertório de conhecimentos e de relações que o sujeito domina. No primeiro nível de complexidade de uma camada, que demarca o tipo de habilidade (representacional, por exemplo) os elementos não se relacionam (ou as relações são inconsistentes). No segundo nível, os mapas, algumas relações são estabelecidas, mas não há interlocuções muito articuladas entre elas. No terceiro nível, sistemas, as relações são estabelecidas em diferentes sentidos, levando em consideração os elementos que compõem a habilidade em questão. Esse sistema pode se conectar com outro sistema, se referindo à mesma habilidade ou habilidade distinta, formando um sistema de sistema que representa uma forma diferenciada de habilidade, que será um elemento da camada posterior, a abstracional. Esses níveis de complexidade dentro de uma camada podem ocorrer de forma recursiva sem que haja mudança da camada, a depender do tipo de habilidade que está sendo desenvolvida.

Como na Teoria de Fischer, algumas teorias consideradas neopiagetianas (Biggs, \& Collis, 1982; Case, 1993; Commons, 2008), se concentram em definir o caminho de aprendizagem como algo recorrente em domínios específicos de conhecimento. Ou seja, as camadas (Fischer, 1980) ou modos de pensamento (Biggs, \& Collis, 1982) podem ser interpretados como passos para que um novo conhecimento, habilidade ou entendimento seja construído. É possível utilizar a estrutura geral para construir uma taxonomia onde definimos camadas gerais e níveis de complexidade dentro das camadas, a fim de interpretar a evolução de algum traço latente em uma área ou domínio específico. Dessa forma, a estrutura que demarca a evolução de habilidades foi utilizada no nosso estudo como base para elaborar um sistema de classificação de respostas denominado como Taxonomia da Complexidade do Entendimento (TCE). Ou seja, os níveis de complexidade descritos para as habilidades foram considerados para descrever o entendimento no domínio específico de conteúdo de Pêndulo Simples.

A TCE, elaborada a partir da estrutura hierárquica da Teoria de Habilidades Dinâmicas, foi utilizada para classificar as respostas dos estudantes a tarefas sobre o conteúdo de Pêndulo Simples, durante uma instrução pautada na atividade experimental investigativa. O sistema é composto de categorias correspondentes a níveis de entendimento, com um formato semelhante à escala Guttman (1944). As questões respondidas pelos estudantes avaliaram o entendimento conceitual e procedimental, e a utilização da TCE possibilitou identificar o nível desse entendimento em diferentes momentos. Como a TCE se apresenta no formato de escala Guttman, os dados classificados de acordo com seus critérios são susceptíveis a uma transformação numérica. Isso significa que podemos gerar uma matriz de respostas numérica que representa não só os acertos em um teste como também o nível de articulação do entendimento.

A classificação dos níveis de entendimento das respostas coletadas em diferentes momentos, transformados em matriz numérica de resposta, possibilitou investigar a aprendizagem sobre o conteúdo de Pêndulo Simples a partir da modelagem dos dados, o que nos forneceu uma métrica passível de comparações. Dessa forma, a aprendizagem, concebida nesse estudo como a evolução dos níveis de entendimento nas duas dimensões, 
procedimental e conceitual, foi investigada a partir do "ganho" de entendimento em cada situação. Para verificar em que medida um entendimento é mais contemplado que outro, ou em que medida o ambiente influencia mais no progresso de um ou outro tipo de entendimento, comparações entre os "ganhos" foram conduzidas. Em suma, utilizamos a TCE para qualificar o entendimento em níveis hierárquicos reportado nas respostas discursivas, geramos uma métrica quantitativa através da modelagem das respostas (discursivas e dicotômicas) transformadas em dados numéricos e a partir dela conduzimos comparações para interpretar o que se aprende sobre Pêndulo Simples em atividades investigativas nos laboratórios material e computacional.

\section{Apresentação do Estudo}

A pesquisa ocorreu em um Instituto Federal de Educação, onde o conteúdo contemplado na unidade temática pelo professor foi o de Pêndulo Simples. Os alunos foram submetidos a uma intervenção didática, não obrigatória, que ocorreu após a instrução formal sobre o conteúdo em sala de aula. Inicialmente os professores foram convidados a colaborar com a pesquisa e um acordo foi feito para que as atividades propostas fossem oferecidas de acordo com o planejamento de conteúdo dos docentes. Dessa forma, a intervenção com atividade experimental investigativa foi realizada em aulas no laboratório (físico e de informática), em horário que não comprometeu as atividades obrigatórias dos estudantes na escola.

\section{Material de intervenção}

Para investigar a aprendizagem sobre conceitos envolvidos no conteúdo de Pêndulo Simples elaboramos dois roteiros específicos com problemas desafiadores no espírito das atividades investigativas propostas por Carvalho (2013). Contudo, a abordagem que realizamos não se restringiu a aspectos conceituais, pois em algumas tarefas o estudante era solicitado a fazer manipulações numéricas e/ou vetoriais.

Dois roteiros foram desenhados para serem aplicados no laboratório de informática e no laboratório de física. Ambos contiveram desafios a serem resolvidos acompanhados de questões que faziam parte do processo investigativo, tais como "qual a hipótese levantada pelo grupo?". Além dessas, outras questões, de natureza mais formal, também faziam parte dos roteiros, tendo como objetivo acessar o entendimento dos estudantes durante o processo. $\mathrm{O}$ roteiro que foi utilizado no laboratório em ambiente material continha 03(três) desafios, além de 03(três) questões formais. Já o roteiro que foi utilizado no laboratório em ambiente computacional continha 02 (dois) desafios, além de 03(três) questões formais.

Os desafios projetados para ambos os ambientes continham os mesmos elementos do conteúdo a serem manipulados, pois tentamos tornar as ações o mais próximas possíveis em termos de entendimento mobilizado, ainda que reconheçamos que em cada tipo de laboratório (computacional e material) outras demandas cognitivas surjam. O propósito foi comparar a aprendizagem em atividades experimentais que 
contiveram o mesmo objetivo didático e que eram o mais semelhantes possíveis; por isso, tanto a simulação quanto o experimento concreto dispuseram de elementos manipuláveis semelhantes em termos de possibilidades de ações. Ainda que demandem ações cognitivas diferentes para lidarem com os objetos de aprendizagem, o conteúdo foi o mesmo, sendo as tarefas solicitadas nos roteiros bem semelhantes. Velasco e Buteler (2017) relatam a existência de aprendizagem conceitual a partir de simulações computacionais, embora não façam uma sistematização de resultados com pareamento no ambiente material. Nesse sentido, tal pareamento é promissor para identificarmos o que difere em termos de aprendizagem de conteúdo, ainda que não seja possível eliminar todas as variáveis que divergem em termos de objetos de aprendizagem.

Dois exemplos de desafios são apresentados na Figura 2.

\begin{tabular}{|l|l|}
\hline $\begin{array}{l}\text { Desafio no } \\
\text { Ambiente } \\
\text { Material }\end{array}$ & $\begin{array}{l}\text { Projete uma situação para encontrar a gravidade local utilizando o Kit fornecido. Qual } \\
\text { * Descreva o experimento que você projetou. } \\
\end{array}$ \\
\hline Como você encontrou o valor da gravidade? \\
$\begin{array}{l}\text { Desafio no } \\
\text { Ambiente }\end{array}$ & disponibilizada. \\
Virtual & $*$ Qual o valor obtido? \\
\hline
\end{tabular}

Figura 2. Exemplo de desafios nos laboratórios em ambientes material e computacional

Para desafios como o explicitado na Figura 2, os estudantes que fizeram a atividade no laboratório em ambiente material tiveram acesso a um kit experimental como mostrado na Figura 3. Eles continham componentes: suporte de fixação, trena, fio, cronômetro e massas aferidas.

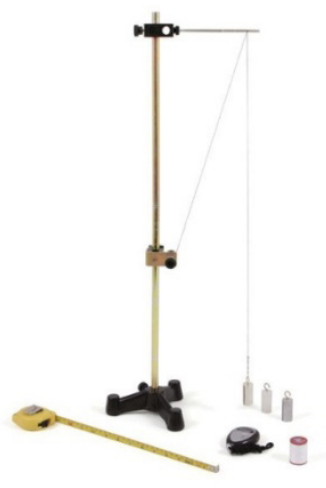

Figura 3. Kit de Pêndulo Simples

Fonte: https://azeheb.com.br/pêndulo-simples.html. Kit Experimental Material

Os estudantes que fizeram o desafio no laboratório em ambiente computacional acessaram a simulação gratuitamente no site https://phet.colorado.edu/pt_BR/ simulation/pendulum-lab. A Figura 04 mostra a simulação utilizada na atividade. Ela 
traz como elementos para manipulação: ajuste de comprimento, modificação do número de pêndulos, medidor de intervalo de tempo, cronômetro gráfico, localização geográfica, gráfico que pode estimar os valores de energia mecânica, além de outros que não foram solicitados na atividade. A partir dos roteiros que estipulavam os desafios, os estudantes deveriam manipular os objetos, materiais ou computacionais, para solucioná-los. Após cada atividade, algumas questões foram colocadas, em ambos os roteiros, indagando sobre o entendimento geral do fenômeno, tais como: "Quais as forças que agem sobre o pêndulo em uma situação de repouso?” As respostas a essas questões do roteiro, entretanto, não foram analisadas nesse estudo.

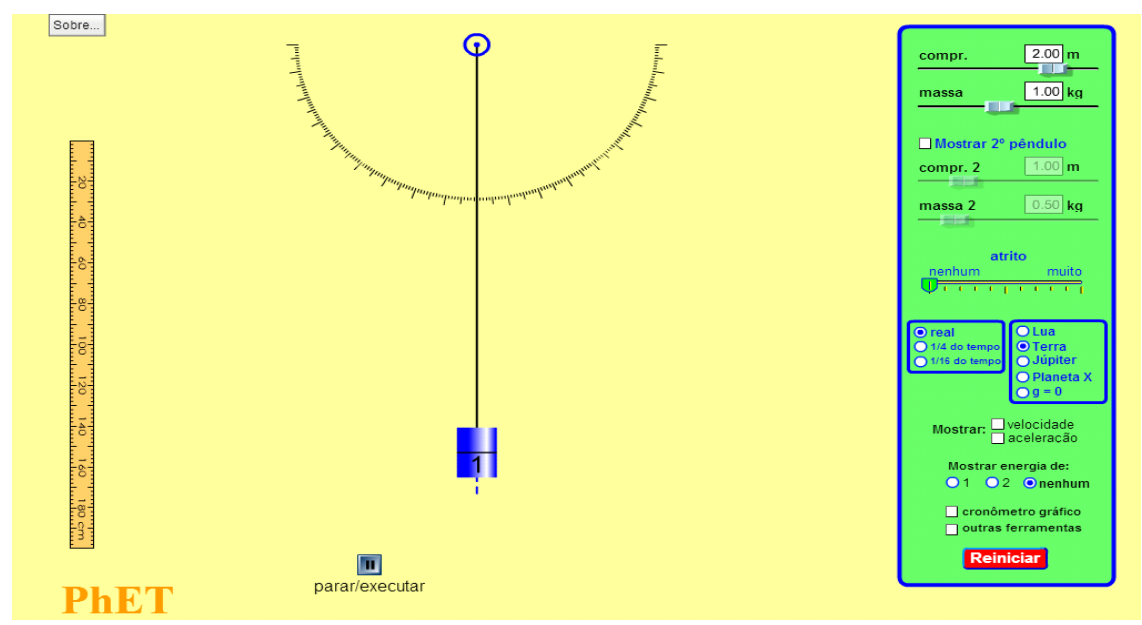

Figura 4. Tela de simulação computacional "Laboratório de Pêndulos"

Fonte: https://phet.colorado.edu/pt_BR/simulation/pendulum-lab

\section{Material de Coleta}

Além das respostas às atividades e questões dos roteiros, os estudantes foram solicitados a responderem testes de conhecimento em 3 diferentes momentos da intervenção. Esses testes consistiram em questões formais sobre o conteúdo de Pêndulo Simples, e tinham como propósito acessar o entendimento sobre os diferentes conceitos que esse tema abarca, de maneira independente do que foi abordado nas atividades. O objetivo de aplicar esses testes foi avaliar a evolução do entendimento formal (se ela ocorreu e de que forma ocorreu) quando os estudantes fizeram uma atividade investigativa em dois diferentes ambientes.

Nesse estudo relatamos a análise feita somente com as respostas aos dois primeiros testes de conhecimento. Esses instrumentos foram sistematizados a partir de um banco de itens baseado em adaptações de questões formais de vestibulares e de livros didáticos, além de outras desenhadas pelos pesquisadores. Primeiramente várias questões foram estabelecidas, de caráter discursivo e dicotômico (alternativas e verdadeiro/falso), abarcando os conceitos de frequência, período, movimento oscilatório, composição de forças no pêndulo, relações entre grandezas. Em seguida classificamos a natureza das 
questões em relação ao tipo de entendimento demandado: conceitual ou procedimental. As questões procedimentais buscavam acessar como os estudantes aplicavam os conhecimentos diante de uma situação-problema. As questões de natureza conceitual visavam acessar a capacidade dos estudantes quanto à utilização de relações entre símbolos, expressões, ideias e representações com as quais eles aprendem a significar o fenômeno ou conceito (Amantes, 2009).

Após a sistematização do banco de itens, ele foi utilizado para a construção dos testes de conhecimento, que foram compostos de questões dicotômicas e questões discursivas. Nas questões de verdadeiro/falso os estudantes tinham que interpretar uma situação, descrita em um enunciado para avaliar sentenças. Nas questões de alternativas os estudantes deveriam escolher uma alternativa correta, dentre outras consideradas como distratores (Hestenes, \& Halloun, 1995). As questões discursivas demandaram a escrita por parte dos estudantes sobre seu entendimento em relação ao conteúdo. As respostas a essas questões permitiram identificar o foco de atenção, o entendimento teórico e como os estudantes utilizavam esse entendimento para resolver alguns problemas. Exemplos de cada tipo de questão estão explicitados na Figura 5.

\begin{tabular}{|l|l|}
\hline Tipo de questão & Questão \\
\hline Ficotômicas (Verdadeiro/ & $\begin{array}{l}\text { Um pêndulo simples de } 10 \mathrm{~m} \text { de comprimento é posto a oscilar } \\
\text { em diferentes locais ao redor do globo terrestre. São anotadas as } \\
\text { medidas correspondentes ao período e frequência de oscilação } \\
\text { realizada quando o pêndulo é colocado no polo norte geográfico, } \\
\text { no equador terrestre e no polo sul geográfico. Considerando que o } \\
\text { valor da aceleração da gravidade nos polos norte e sul geográfico } \\
\text { vale 9,823m/s² e na linha do equador terrestre vale } 9,789 \mathrm{~m} / \mathrm{s}^{2} \text { avalie } \\
\text { os seguintes itens classificando-os em verdadeiro(V) ou falso(F). } \\
\text { ( ) O período do pêndulo independe do local geográfico onde o } \\
\text { mesmo é posicionado; } \\
\text { ( ) O período do pêndulo nos polos assume valores diferentes } \\
\text { devido a estarem em posições opostas; } \\
\text { ( ) O período do pêndulo na linha do equador terrestre vale } \\
\text { aproximadamente 6,35s } \\
\text { ( ) A frequência do pêndulo no polo norte é de 1,6Hz; } \\
\text { ( ) No equador a frequência e o período de oscilação do pêndulo } \\
\text { simples terão o mesmo valor absoluto; } \\
\text { ( ) No polo norte o valor da frequência do pêndulo simples será a } \\
\text { mesma que quando colocado no polo sul; } \\
\text { ( ) Se a massa do pêndulo for substituída por outra massa de valor } \\
\text { diferente o período do pêndulo não sofrerá alteração independente } \\
\text { do local onde for posicionado; }\end{array}$ \\
\hline
\end{tabular}

Figura 5. Exemplos de diferentes questões utilizadas nos testes de conhecimento (continua) 


\begin{tabular}{|c|c|}
\hline Tipo de questão & Questão \\
\hline Dicotômicas (Alternativas) & $\begin{array}{l}\text { Determine o período de oscilação de um pêndulo simples com } 2,0 \mathrm{~m} \\
\text { de comprimento, que executa pequenas oscilações em um local } \\
\text { onde } g=10 \mathrm{~m} / \mathrm{s}^{2} \text {. Despreze influências do ar e considere } \pi \text { igual a } 3 \text {. } \\
\text { (a) } 1 \text { minuto; } \\
\text { (b) } 30 \text { segundos; } \\
\text { (c) } 45 \text { segundos; } \\
\text { (d) } 0,45 \text { segundos; } \\
\text { (e) } 0,30 \text { segundos; }\end{array}$ \\
\hline Discursivas & $\begin{array}{l}\text { Faça a descrição das forças que agem no movimento oscilatório de } \\
\text { um pêndulo simples. }\end{array}$ \\
\hline
\end{tabular}

Figura 5. Exemplos de diferentes questões utilizadas nos testes de conhecimento (continuação)

Fonte: Dados da pesquisa

Os testes cujas respostas foram analisadas nesse estudo (Teste 1 e Teste 2) podem ser descritos da seguinte forma:

Teste 1 - Continha oito questões assim classificadas:

Questão 1: aberta conceitual sobre Força; Questão 2: dicotômica conceitual de múltipla escolha sobre Força; Questão 3: dicotômica procedimental de múltipla escolha sobre Período. Questão 4: discursiva procedimental, relação entre grandezas (Período e Comprimento Linear). Questão 5: discursiva procedimental, sobre Período; Questão 6: dicotômica conceitual de múltipla escolha sobre o conteúdo de Pêndulo Simples. Questão 7: dicotômica procedimental com treze itens V ou F sobre Força, Período, Frequência e relação entre grandezas (Comprimento e Deslocamento). Questão 8: dicotômica conceitual de V ou F sobre Força, com oito itens sobre Período, Frequência e relação entre grandezas (Comprimento, Ângulo, Massa e Período).

Teste 2 - Continha onze questões assim classificadas:

Questão 1: discursiva conceitual sobre Força; Questão 2: dicotômica conceitual de múltipla escolha sobre relações entre grandezas (Velocidade linear e Aceleração da gravidade); Questão 3: discursiva conceitual, sobre relação entre grandezas (Massa, Comprimento e Período); Questão 4: discursiva procedimental sobre relação entre grandezas (Período e Massa); Questão 5: discursiva procedimental sobre relação entre grandezas (Período e Comprimento); Questão 6: discursiva procedimental sobre relação entre as grandezas (Período e Deslocamento); Questão 7: dicotômica procedimental de múltipla escolha sobre Período; Questão 8: discursiva procedimental sobre Período; Questão 9: dicotômica procedimental com treze itens V ou F sobre Força, Período, Frequência e relações entre grandezas (Comprimento e Deslocamento); Questão 10: dicotômica procedimental com oito itens V ou F sobre Força, Período, Frequência e relação entre grandezas (Comprimento, Ângulo, Massa e Período); Questão 11: de natureza procedimental com sete itens V ou F sobre Força, Período, Frequência e relação 
entre as grandezas (Período, Frequência e Massa).

Apesar de conterem números distintos de questões, os testes abarcaram essencialmente os mesmos conteúdos e muitos itens eram bem semelhantes, sendo alguns repetidos do Teste 1 no Teste 2, o que nos fornece o parâmetro para comparar a diferença de desempenho e interpretá-la como um ganho no entendimento. As questões dicotômicas foram avaliadas em termos de certo/errado. A avaliação das questões discursivas demandou a criação de um sistema categórico específico, por isso elaboramos uma taxonomia que abarcou os conceitos possíveis de serem encontrados nas respostas, atribuindo níveis hierárquicos a depender da complexidade que estes conceitos foram explicitados. Esse procedimento é descrito na próxima seção.

\section{Sujeitos e contexto}

Os roteiros elaborados foram aplicados no laboratório de Física e no laboratório de Informática em horário em que os estudantes não tinham atividades obrigatórias na escola. Como se tratou de uma Instituição Federal onde os alunos ficam em período integral, agendamos quatro (4) aulas para a realização da intervenção, sendo cada aula de 50 minutos (duas aulas geminadas/dia), em horários que na grade constavam como "vagos". No laboratório em ambiente computacional disponibilizou-se um computador para cada dupla ou trio de estudantes, que trabalharam com a simulação via acesso direto à internet. No laboratório em ambiente material os estudantes trabalharam em bancadas, em grupos de 04 a 06 componentes. Ao todo foram 06 kits de atividades experimentais.

Apesar de poderem interagir no momento da realização da atividade experimental, cada estudante deveria elaborar de modo particularizado uma resposta aos desafios propostos nos roteiros. A condução de todos os procedimentos de coleta, incluindo os testes de conhecimento, correspondeu a 7 horas/aulas. Os testes foram aplicados na sala de aula, no horário da disciplina, pelo professor de física, em 1 aula de 50 minutos cada teste.

Cada onda de medida contou com diferentes números de participantes. $\mathrm{Na}$ primeira participaram 124 estudantes, 62 eram do sexo masculino e 62 do sexo feminino. Destes, 47 cursavam Eletrotécnica, 15 cursavam Geologia, 24 cursavam Química, 20 cursavam Eletrônica e 18 cursavam Refrigeração e Climatização. Na segunda onda, contamos com 87 estudantes, sendo 46 do sexo masculino e 41 do sexo feminino. Desses, 47 eram do curso de Eletrotécnica, 08 do curso de Geologia, 06 do curso de Química, 08 do curso de Eletrônica e 18 do curso de Refrigeração e Climatização.

Para a análise, foram utilizados os dados dos estudantes que responderam a maioria das questões dos dois testes, pois o método de estimativa utilizado não converge para aqueles que não respondem os itens. Eliminamos aqueles alunos que não responderam a um dos dois testes ou deixaram 95\% das respostas em branco. Efetivamente nossa amostra contou com 87 estudantes, dos quais 55 realizaram a atividade no laboratório em ambiente computacional, e 32 no laboratório em ambiente material. Os estudantes, 
e no caso de menores os seus pais, assinaram o TCLE (Termo de Consentimento Livre Esclarecido).

Para que todos os estudantes tivessem igual oportunidade de aprendizagem, a intervenção ocorreu de modo que quem realizou a atividade no laboratório em ambiente computacional no primeiro momento foi para o laboratório em ambiente material em um segundo momento e vice-versa; ou seja, todos fizeram as mesmas atividades. Contudo, avaliamos aqui somente os dados dos dois grupos após o primeiro momento, a fim de verificar a influência do ambiente na aprendizagem. O Teste 2 delimita o momento entre as mudanças.

As etapas da pesquisa podem assim ser sintetizadas:

1- Teste1: Ocorreu antes da realização das atividades experimentais, e os estudantes tiveram 50 minutos para responder as questões em sala de aula.

2- Primeiro Momento: realização da atividade experimental nos dois ambientes. O tempo para realização das atividades desse primeiro momento foi de duas aulas de 50 minutos cada. Após a conclusão da atividade o professor fez um breve fechamento explicando o fenômeno estudado e os estudantes entregaram os relatórios.

3- Teste2: Ocorreu entre o primeiro momento e o segundo momento, em que houve a troca de ambientes. Foi realizado em sala de aula, com duração de 50 minutos.

4- Segundo Momento: realização da atividade experimental nos dois ambientes, com a troca dos estudantes. O tempo para realização das atividades desse momento foi de duas aulas de 50 minutos cada, com o fechamento semelhante ao do primeiro momento.

5- Teste 3: Depois da inversão das turmas, foi ainda aplicado um terceiro teste, que avaliou o entendimento construído em todo o processo de intervenção.

A coleta de dados atendeu ao planejamento da sequência de conteúdo estabelecida pelo professor, ou seja, antes de iniciarmos a abordagem didática houve um acordo com o professor das turmas para que esse estudo atendesse à demanda do mesmo em relação ao ensino do conteúdo de Pêndulo Simples. Ressaltamos que os participantes da pesquisa não haviam, em um outro momento, experienciado realizar atividades de cunho experimental investigativo de Física ou de outras disciplinas nos laboratórios em ambiente computacional e material.

\section{Método}

Para responder às questões que nortearam esse estudo, consideramos o entendimento como o desempenho dos estudantes nos testes de conhecimento. A aprendizagem, nessa perspectiva, pode ser considerada como a evolução desse entendimento. Portanto, averiguamos se houve progresso no entendimento (aprendizagem) a partir da comparação do desempenho nos dois diferentes momentos de realização dos testes. Como estamos lidando com dados numéricos, é necessário que essa comparação seja feita de maneira a garantir que as inferências sobre as possíveis diferenças de desempenho não seja devido ao acaso ou à dispersão dos dados, ou seja, 
se elas são significativas. Faz-se necessário, dessa forma, a utilização de testes estatísticos para avaliar se o que obtermos de divergência entre os ganhos de entendimento são significativos em certo intervalo de confiança, o que dá maior robustez para a interpretação dos resultados.

Essa perspectiva de integração de métodos qualitativos e quantitativos tem sido defendida por muitos autores que discutem a questão do pluralismo metodológico para conferir maior objetividade, validade e confiabilidade às pesquisas educacionais (Golafshani, 2003; Shaffer, \& Serlin, 2004). O argumento é a favor de um pragmatismo metodológico, em que devemos utilizar técnicas e métodos que são mais coerentes às questões de pesquisa que propomos (Tavares, Amantes, \& Vieira, 2012). Quando investigamos um fenômeno educacional cuja questão demanda comparações de atributos, como estudos de efetividade ou causalidade, por exemplo, as indicações sempre convergem para uma metodologia quantitativa, uma vez que as garantias para avaliar a efetiva mudança devem ir além da mera inferência pautada em descrições (Amantes, Coelho, \& Marinho, 2015).

Compartilhando dessa visão bricouler (cf. Vieira, 2011; Kincheloe, 2001) para a metodologia, conduzimos nosso estudo por etapas em que houve análises qualitativas e quantitativas do mesmo dado, uma vez que nossas questões subtendem a comparação de "ganhos" no entendimento nos diferentes ambientes. Primeiramente realizamos uma análise qualitativa das respostas a questões discursivas dos estudantes presentes nos testes aplicados a partir de uma taxonomia elaborada para esse fim. Em seguida transformamos as categorias de análise em dados numéricos o que, em conjunto com o resultado das questões dicotômicas dos testes, nos forneceu uma matriz de respostas numéricas. Tendo em vista que o escore de um teste é descrito em uma escala ordinal e queremos avaliar o ganho, ou seja, a diferença entre as medidas de desempenho, realizamos a Modelagem Rasch (Rasch, 1964) para obter uma escala intervalar, o que atende a critérios específicos de testes estatísticos clássicos que comparam diferenças de médias, como a ANOVA por exemplo. Além disso, tal modelagem nos fornece informações sobre a validade e confiabilidade do teste, assim como do modelo adotado para interpretar a matriz de dados, trazendo garantias sobre a adequação dos instrumentos de coleta e da classificação feita para os itens (conceitual e procedimental), a partir da qual avaliamos a natureza do entendimento.

As duas questões desse estudo, tanto a que se refere à aprendizagem devido ao laboratório de ensino (computacional ou material) quanto à outra referente ao tipo de entendimento mais mobilizado (conceitual ou procedimental) na atividade investigativa, foram estudadas pela comparação dos ganhos no entendimento e, portanto, pela aplicação de testes estatísticos a medidas relativas ao entendimento. No primeiro caso, o entendimento foi inferido a partir das medidas de proficiência dos sujeitos, obtidas pela modelagem em uma escala intervalar de logits. No segundo, a inferência sobre o desempenho foi feita a partir das medidas das dificuldades dos itens, estabelecidas na mesma escala. Isso porque podemos entender o progresso por meio de 
duas perspectivas: o quanto as pessoas ganham em proficiência no decorrer do tempo ou o quanto o teste fica mais fácil de um momento para o outro (Bond, \& Fox, 2001). Como a segunda questão se refere ao entendimento dimensionado pela natureza dos itens respondidos, utilizamos os parâmetros desses itens para analisar o ganho, obtidos também pela modelagem.

A seguir descrevemos o método de análise categórica das respostas discursivas, essencial para gerar a matriz numérica empregada na análise quantitativa. Logo após descrevemos brevemente o método de modelagem que nos forneceu i) os parâmetros para avaliar a validade dos testes e ii) as escalas de proficiência e dificuldade dos itens, utilizadas como medidas para avaliar o ganho no entendimento.

\section{Categorização das Respostas e Matriz Numérica}

A categorização das respostas discursivas dos testes foi realizada com base na Taxonomia de Complexidade do Entendimento (TCE). As dicotômicas foram classificadas em 0 (se a resposta fosse incorreta) e 1 (se a resposta fosse correta).

O sistema categórico (TCE) foi inspirado na análise da estrutura lógica e na ordem hierárquica de níveis de complexidade do entendimento (Fischer, 1980). A perspectiva de interpretação de tal taxonomia está na lógica da ideia ou pensamento descrito em palavras, não na exatidão da resposta em relação ao parâmetro acadêmico. Isso significa que, ao avaliar uma resposta de um estudante, inferimos sobre o nível de articulação de seu entendimento em relação a um conteúdo a partir dos elementos que ele reporta e de como ele relaciona tais elementos. A Teoria de Habilidades Dinâmicas (Fischer, 1980) propõe que um traço latente como a habilidade (no nosso caso o entendimento) se desenvolve em níveis de complexidade dentro das camadas de desenvolvimento cognitivo, em domínios específicos de conhecimento. Os níveis menos complexos correspondem a uma habilidade pouco articulada, com elementos desconexos e até mesmo equivocados. Os níveis mais complexos englobam os menos complexos mas com um nível melhor de articulação entre os elementos, e assim os elementos equivocados passam a ser reconhecidos como tal. Dessa forma, o foco da TCE está em identificar os elementos relevantes do entendimento em relação ao conceito científico e avaliar como esses elementos estão relacionados na resposta, identificando a articulação da ideia, e não a exatidão em relação ao parâmetro acadêmico. A estrutura da taxonomia foi adaptada da proposição teórica da Teoria de Habilidades Dinâmicas, inicialmente realizada por Amantes (2009) para diferentes conteúdos, Coelho (2011) para corrente elétrica, Regebe e Amantes (2013) para conteúdo de lógica de programação. As questões discursivas foram analisadas segundo a TCE que elaboramos. A Figura 6 apresenta um exemplo do sistema. 


\begin{tabular}{|c|c|c|c|c|}
\hline Conceito & Questão & & & Classificação \\
\hline \multirow{7}{*}{ : } & \multirow{7}{*}{ 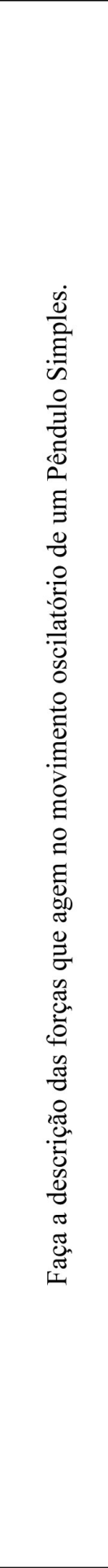 } & \multirow{7}{*}{ 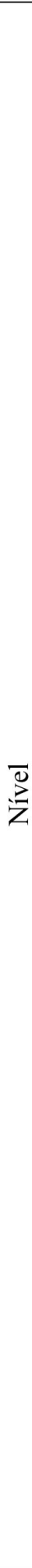 } & Categoria & Exemplos \\
\hline & & & $\begin{array}{l}\text { Q1F1: } \\
\text { Cita a existência de duas } \\
\text { componentes relevantes: } \\
\text { Peso e tração. Contudo a } \\
\text { ideia pode não estar bem } \\
\text { articulada, apresentando } \\
\text { elementos contraditórios } \\
\text { ou equívocos. }\end{array}$ & $\begin{array}{l}\text { "Peso, tração do fio e normal." } \\
\text { (Estudante 18) }\end{array}$ \\
\hline & & & $\begin{array}{l}\text { Q1F2: } \\
\text { Cita Peso e tração e } \\
\text { pode explicitar algum } \\
\text { tipo de relação entre as } \\
\text { componentes. } \\
\text { A resposta ainda pode se } \\
\text { apresentar pouco } \\
\text { articulada. }\end{array}$ & $\begin{array}{l}\text { "Força peso -massa x gravidade e tração -força } \\
\text { do fio que segura o pêndulo." } \\
\text { (Estudante } 01 \text { ) }\end{array}$ \\
\hline & & & $\begin{array}{l}\text { Q1F3: } \\
\text { Cita as grandezas Peso e } \\
\text { Tração, explicitando a } \\
\text { ideia de composição de } \\
\text { forças. } \\
\text { A resposta apresenta } \\
\text { uma articulação } \\
\text { incipiente sobre as } \\
\text { componentes do peso }\end{array}$ & $\begin{array}{l}\text { "Tração e a componente } x \text { do peso." } \\
\text { (Estudante 12) } \\
\text { (Estudante 15) }\end{array}$ \\
\hline & & & \multirow{2}{*}{$\begin{array}{l}\text { Q1F4: } \\
\text { Cita as grandezas Peso e } \\
\text { Tração, explicitando a } \\
\text { ideia de composição de } \\
\text { forças em dois eixos. } \\
\text { Ainda que também } \\
\text { incipiente, as respostas } \\
\text { nessa categoria } \\
\text { apresentam a ideia de } \\
\text { decomposição em dois } \\
\text { eixos. }\end{array}$} & $\begin{array}{l}\text { Tração e as c omponentes da força peso nas } \\
\text { direções "x" e "y". } \\
\text { (Estudante 96) }\end{array}$ \\
\hline & & & & 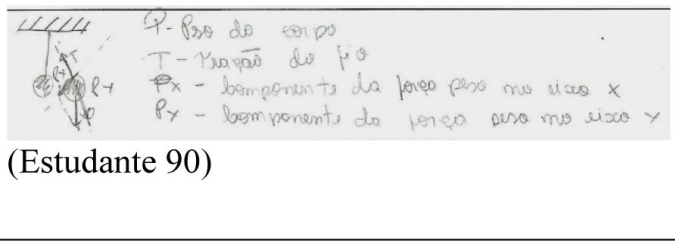 \\
\hline & & & $\begin{array}{l}\text { Q1F5: } \\
\text { Cita as grandezas Peso e } \\
\text { Tração, explicitando a } \\
\text { ideia de composição de } \\
\text { forças em dois eixos com } \\
\text { elementos para indicar o } \\
\text { peso como resultante. } \\
\text { As respostas dessa } \\
\text { categoria apresentam um } \\
\text { nível de articulação da } \\
\text { ideia mais complexo. }\end{array}$ & $\begin{array}{l}\text { (...) tração(T) exercida pelo fio e o peso }(\mathrm{P}) \text {, que } \\
\text { pode ser decomposto segundo as direções da } \\
\text { tangente e da normal à trajetória. } \\
\text { (Estudante } 113 \text { ) }\end{array}$ \\
\hline
\end{tabular}

Figura 6. Categorização das respostas discursivas (continua) 


\begin{tabular}{|c|c|c|c|c|}
\hline Conceito & Questão & \multicolumn{3}{|c|}{ Classificação } \\
\hline \multirow{3}{*}{ 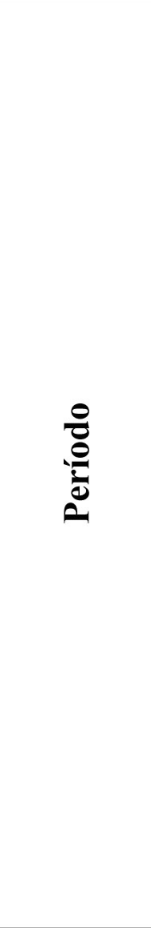 } & \multirow{3}{*}{$\begin{array}{l}\text { Determine o } \\
\text { período de } \\
\text { oscilação de um } \\
\text { Pêndulo simples } \\
\text { com } 2,0 \mathrm{~m} \text { de } \\
\text { comprimento, } \\
\text { que executa } \\
\text { pequenas } \\
\text { oscilações em } \\
\text { um local onde a } \\
\text { aceleração da } \\
\text { gravidade vale } \\
10 \mathrm{~m} / \mathrm{s}^{2} . \\
\text { Despreze } \\
\text { influências do } \\
\text { ar e considere } \\
\pi=3 .\end{array}$} & \multirow{3}{*}{$\sum^{\bar{d}}$} & $\begin{array}{l}\text { Q10P1: } \\
\text { Explicitou um elemento que } \\
\text { pode indicar o entendimento } \\
\text { sobre o conteúdo (resposta } \\
\text { correta ou que ação correta) } \\
\text { mas não apresentou os } \\
\text { elementos do raciocínio. }\end{array}$ & $\begin{array}{l}\mathrm{T}=2,7 \mathrm{~s} \\
\text { (Estudante 33) }\end{array}$ \\
\hline & & & $\begin{array}{l}\text { Q10P2: } \\
\text { Explicitou mais de um } \\
\text { elemento que indica um } \\
\text { raciocínio parcialmente } \\
\text { coerente, pois a } \\
\text { dedução/resposta pode } \\
\text { apresentar elementos pouco } \\
\text { articulados ou equivocados }\end{array}$ & $\begin{array}{l}\mathrm{T}=2 \pi \sqrt{ } \mathrm{l} / \mathrm{g} \rightarrow \mathrm{T}=2 \pi \sqrt{ } \mathrm{l} / 6 \mathrm{gt} \rightarrow \\
(\mathrm{T} / 2 \pi)^{2}=(\sqrt{ } \mathrm{l} / \mathrm{g})^{2} \rightarrow 1 / 4 \pi^{2}=1 / \mathrm{g} \rightarrow \\
1=\mathrm{g}^{2} / 4 \pi^{2} \rightarrow \mathrm{T}=2 \pi \sqrt{\mathrm{gT} / 4 \pi^{2} \rightarrow} \\
\mathrm{T}=2 \pi \sqrt{\mathrm{gt}} / 2 \pi^{2} \cdot \mathrm{gt} \rightarrow \\
\mathrm{T}=2 \pi \cdot 1 / 2 \sqrt{ } 3 \pi^{2} \rightarrow \\
\mathrm{T}=1 / \sqrt{3} \pi \cdot \sqrt{3} / \sqrt{ } 3=\sqrt{ } 3 \pi / 3 \mathrm{~s} . \\
\text { (Estudante 90) }\end{array}$ \\
\hline & & & $\begin{array}{l}\text { Q10P3: } \\
\text { Explicitou mais de um } \\
\text { elemento que indica um } \\
\text { raciocínio coerente, pois } \\
\text { todos os elementos da } \\
\text { resposta apresentam relações } \\
\text { e articulações com exatidão. }\end{array}$ & 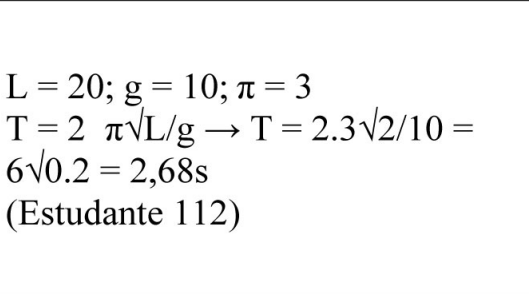 \\
\hline
\end{tabular}

Figura 6. Categorização das respostas discursivas (continuação)

Fonte: Dados da Pesquisa.

Para a questão: Faça a descrição das forças que agem no movimento oscilatório de um Pêndulo Simples

Inicialmente fizemos uma leitura das respostas identificando alguns padrões que poderiam ser utilizados para elaborar categorias hierárquicas. Um dos padrões foi a citação conjunta de tração e peso, o que nos levou a basear o sistema categórico na qualificação da relação entre essas duas grandezas. Procedemos com a descrição de algumas categorias possíveis a partir dos padrões de respostas identificados na leitura. Em seguida, buscamos classificar as respostas de acordo com essas categorias pré-estabelecidas, identificando possíveis inconsistências no sistema categórico. Esse processo foi feito repetidas vezes, até chegarmos a um sistema que foi possível aplicar à base de dados obtida. Isso feito, realizamos uma classificação pareada de 50 respostas, entre dois pesquisadores, e avaliamos que o nível de concordância (em torno de $80 \%$ ) foi suficiente para a adoção do sistema.

Para as respostas a essa questão, elaboramos cinco níveis, que procuraram avaliar se o estudante reconhecia as forças Peso e Tração e como ele articulava essas forças para entender o movimento do Pêndulo. No primeiro nível, a resposta indica apenas que o estudante reconhece a existência dessas forças, pois não explicita nada; além disso, 
pode apresentar ou não elementos desconexos ou equivocados. No segundo nível, além de reconhecer a existência dessas forças, a resposta apresenta uma ideia incipiente de relações entre as diferentes grandezas que compõem o sistema, como no caso de explicitar que tração está relacionada ao que segura o pêndulo e o peso/massa à força da gravidade. No terceiro nível, além de explicitar as componentes e indicar a existência de relações na movimentação do pêndulo, a resposta apresenta indícios de uma ideia mais complexa sobre composição vetorial, ainda que incipiente ou incompleta. Nas respostas do quarto nível há uma explicitação do entendimento da composição vetorial do peso em dois eixos, além do reconhecimento da tração. Finalmente, as respostas do quinto nível apresentam uma articulação mais complexa, pois além de todos esses elementos já descritos, elas incorporam uma descrição detalhada do movimento em virtude da relação entre as diferentes grandezas.

Para a questão de cálculo do Período, consideramos como primeiro nível respostas que se remetem a um elemento, seja a resposta correta, seja a proposição da fórmula para resolução do problema, sem que haja desenvolvimento do raciocínio; ou seja, temos um indicativo de entendimento, mas sem elementos suficientes para fazer maiores inferências sobre esse entendimento. No segundo nível, podemos identificar um raciocínio para resolução da questão a partir da explicitação de ideias coerentes na execução do cálculo, o que representa a articulação de mais de um elemento. Mas nesse nível há falta de articulação que leva a equívocos, tanto na manipulação da fórmula quanto nos valores numéricos encontrados, indicando que as relações entre os elementos ainda não estão bem estabelecidas. No terceiro nível, além de haver vários elementos articulados demonstrando o raciocínio, as relações são bem estabelecidas e coerentes.

Entendemos que esse sistema, assim desenhado, tem um caráter que permite associá-lo à escala Guttman (1944), pois os níveis mais complexos abarcam os anteriores, uma vez que lidamos com o nível de articulação do entendimento como conteúdo principal de análise. Dessa forma, adotamos a estrutura da escala Guttman para transformar as categorias em dados numéricos, codificados como 0 e 1 . A Figura 7 apresenta um exemplo de resposta discursiva categorizada como em um nível 3 de complexidade, de uma questão que poderia abarcar até o nível 5. Isso significa que, para a questão sobre Força acima, por exemplo, a resposta assim classificada apresenta o reconhecimento de peso e tração (nível 1), demonstra em certa medida uma relação entre as grandezas envolvidas no movimento (nível 2) e ainda explicita algum entendimento sobre composição vetorial (nível 3), mas não em dois eixos (nível 4) e tampouco descreve o movimento de maneira articulada (nível 5).

\begin{tabular}{|c|c|c|c|c|c|}
\hline Estudante & \multicolumn{5}{|c|}{ Conceito: Força } \\
\hline \multirow{2}{*}{12} & Q1F1 & Q1F2 & Q1F3 & Q1F4 & Q1F5 \\
\cline { 2 - 6 } & 1 & 1 & 1 & 0 & 0 \\
\hline
\end{tabular}

Figura 7. Transformação de categorias em dados dicotômicos

Fonte: Dados da pesquisa. 
Utilizando esses critérios, obtivemos uma classificação das respostas no nível qualitativo transformada em dado numérico, que foi submetido à modelagem Rasch para obtenção da escala intervalar.

\section{Modelagem Rasch e Validação dos Testes}

O modelo desenvolvido por Rasch (1964) prevê que a probabilidade de sucesso ou fracasso em uma tarefa depende de um atributo do sujeito (no nosso caso o entendimento) e a dificuldade da tarefa (parâmetros de dificuldade dos itens). A escala intervalar obtida pela modelagem é definida como aquela em que os intervalos entre os valores que dizem respeito à proficiência são iguais e, portanto, passíveis de comparação. Ela permite comparar diferenças entre as medições, mas não permite concluir quanto à magnitude absoluta das medições (Chisnall, 1973), uma vez que não há um zero absoluto. As medidas são calculadas a partir de um ponto, fixado arbitrariamente, no qual as diferenças entre os valores podem ser interpretadas significativamente. Logo, nessa escala os números ordenam os objetos (itens) tal que a diferença entre eles corresponda às distâncias entre os objetos no atributo que está sendo mensurado, ou seja, pode-se fazer o pareamento entre as diferenças de proficiência e as diferenças do traço latente (Chisnall, 1973; Parasuraman, 1991). Como tal escala permite a aplicação de testes estatísticos clássicos de diferenças de médias, a utilizamos para avaliar as diferenças de ganho no entendimento para responder às questões levantadas.

Submetemos a matriz de dados dicotômicos à modelagem Rasch utilizando o software Winsteps (Linacre, \& Wright, 2000). Para avaliar a validade do teste, em termos do quanto ele se ajusta para identificar o traço desejado (no caso o entendimento) de acordo com um modelo teórico (a hipótese é a de que temos pelo menos duas dimensões- a conceitual e procedimental), utilizamos algumas estatísticas fornecidas pela modelagem: i) para a avaliação da dimensionalidade conduzimos a análise dos resíduos, que busca encontrar o número mínimo de contrastes que expliquem o máximo de variância possível; ii) para avaliar o quanto as medidas são adequadas para interpretar a matriz de dados nos valemos da análise da explicação da variância na dimensão Rasch e comparação entre as porcentagens da variância modelada e empírica; iiii) para avaliação da coerência interna do teste utilizamos o alfa de cronbach; e iii) para identificar se os itens do teste estão bem ajustados utilizamos a estatística MNSQ (Show Mean-Square Instead of T-Standardized Fit Statistics) INFIT e OUTFIT.

A Figura 8 sintetiza todas estatísticas para o Teste 1 e o Teste 2, com exceção do MNSQ, que é calculado para cada item em particular.

Para investigar se o teste dimensiona uma dimensão ou mais, avaliamos os resíduos, cuja análise busca encontrar o número mínimo de contrastes que expliquem o máximo de variância possível. Esses valores levantam argumentos a favor ou contra a unidimensionalidade e, por isso, deve-se avaliar qualitativamente os itens, a fim de identificar se as diferenças dos traços que pretendem mensurar são suficientemente distintas para que mais de uma dimensão seja considerada. 


\begin{tabular}{|l|l|l|l|}
\hline & & Teste 1 & Teste 2 \\
\hline Variância & Modelada & $23.4 \%$ & $25.0 \%$ \\
\hline & Empírica & $23.0 \%$ & $25.2 \%$ \\
\hline & Primeiro Contraste & $5.0-11.4 \%$ & $5.0-9.1 \%$ \\
\hline Alfa de Cronbach & & 0.77 & 0.74 \\
\hline Confiabilidade itens & & 0.91 & 0.94 \\
\hline
\end{tabular}

Figura 8. Estatística de Ajuste do Teste 1 e Teste 2

Fonte: Dados da pesquisa.

Uma das formas de análise dos resíduos diz respeito à variância não explicada pelo primeiro contraste. Ela foi de 5.0 para os dois testes, correspondendo a $11.4 \%$ no primeiro e a $9.1 \%$ no segundo. Elas estão acima do limite apontado como ideal para considerar o instrumento como unidimensional $(2,0)$ (Linacre, 2014). Isso quer dizer que o teste provavelmente acessa mais de um tipo de conhecimento, o que está de acordo com nosso pressuposto de que pelo menos duas dimensões podem ser consideradas: a conceitual e a procedimental. Podemos considerar que uma parte razoável da variância é explicada pela dimensão Rasch nos dois testes (23,0 \% no Teste 1, 25,2 \% no Teste 2). Isso significa que conseguimos dimensionar $23 \%$ e $25,2 \%$ da variabilidade dos padrões de respostas inferindo que elas são devido a um elemento específico do teste, que consideramos ser o entendimento sobre Pêndulo Simples. Do ponto de vista de um fenômeno educacional esse é um resultado razoável, já que lidamos com muitas variáveis para avaliar o entendimento por um único instrumento. Podemos avaliar a validade do teste verificando o quanto a variância modelada se aproxima da empírica (Linacre, 2014); nesse caso, estamos testando se o padrão de respostas empíricas se aproxima do esperado, tendo a matriz de respostas como parâmetro. No nosso caso, temos, nos dois testes, as variâncias bem próximas, sendo que o segundo parece ter um melhor ajuste. A consistência interna foi avaliada pelo alfa de cronbach, que se mostrou razoável $(0,77$ para o primeiro teste e 0,74 para o segundo).

No que se refere ao ajuste dos itens, a modelagem nos fornece o valor da confiabilidade, que se mostrou alta tanto para o Teste $1(0,91)$ como para o Teste $2(0,94)$, indicando boa adequação. Outro parâmetro que avaliou esse ajuste foi o MNSQ, Infit e Outifit. Variações entre 0,5 e 1,5 de Infit e Outfit na estatística MnSq são aceitáveis (Linacre, \& Wright, 1991), sendo que valores maiores indicam que há um padrão de respostas inesperado para os indivíduos, indicando que pode haver sujeitos que acertam itens muito mais difíceis do que sua proficiência estimada ou errar aqueles cuja probabilidade de acerto seja alta (Wright, \& Stone, 2004). Linacre e Wright (1991) apontam ainda que um valor elevado de Infit pode indicar que o item está sendo acertado por sujeitos não esperados, desafiando sua validade. A análise dos índices de Outfit e Infit mostrou que nenhum item degradou a medida, ou seja, não houve itens com estatística menor que 0,5 ou maior que 1,5 , o que é também um indicativo de boa adequação.

Em síntese, a modelagem Rasch nos deu suporte para considerar como válido 
o teste para acessar pelo menos duas dimensões, que estamos interpretando como conceitual e procedimental, além de fornecer parâmetros para considerar os itens bem ajustados e confiáveis.

\section{Análise e resultados}

Para investigar o efeito da aplicação da atividade de natureza investigativa nos dois tipos de laboratório utilizamos os dados de proficiência e de dificuldade dos itens fornecidos pela modelagem Rasch, realizada no Winsteps. Nesse estudo investigamos:

1- Aprendizagem segundo o ambiente: averiguamos se existiu diferença de aprendizagem dos estudantes no laboratório em ambiente computacional e no laboratório em ambiente material, pela comparação das médias de ganho no desempenho em cada teste.

2- Natureza do conhecimento aprendido: identificamos que tipo de entendimento (procedimental e conceitual) foi mais contemplado na intervenção, comparando a diferença da média da dificuldade dos itens em cada teste, de acordo com sua dimensão.

\section{Estudo 1}

A análise da diferença da aprendizagem dos estudantes ocorreu em função do ganho no entendimento, que pode ser descrito como:

\section{Ganho $=$ Proficiência Teste $2-$ Proficiência Teste 1}

Como o desempenho está descrito em uma escala intervalar fornecida pela modelagem Rasch, pudemos conduzir análise de comparações aplicando testes cujo pressuposto compreende esse tipo de variável, como a ANOVA.

Antes de avaliarmos a aprendizagem em termos do ambiente, verificamos se o ganho em geral foi positivo. Identificamos que do Teste 1 para o Teste 2 os estudantes ganharam $0,61 \operatorname{logit}(\mathrm{SD}=1,19)$, em uma escala que variou de 0,16 logit até 0,87 logit. $\mathrm{O}$ valor do desvio padrão se mostra relativamente alto, ou seja, existe uma grande dispersão em relação ao ganho no entendimento. Isso significa que houve diferença no entendimento sobre o Pêndulo Simples positiva (ganho de entendimento) entre duas ocasiões de medida (antes e depois da instrução) com uma alta variabilidade entre os sujeitos.

Para identificar se houve aprendizagem diferenciada segundo o ambiente, utilizamos testes estatísticos para avaliar se as diferenças das médias de ganho no virtual e no material são significativas, ou seja, se não são devido ao acaso ou a um comportamento aleatório dos dados. O teste que aplicamos para verificar as diferenças foi ANOVA, que é um teste de hipótese sobre a igualdade de médias. A hipótese nula desse teste pressupõe que as médias são iguais, por isso a estatística gerada é um parâmetro que nos leva a aceitar ou não essa hipótese a depender do nível de significância. Quando avaliamos em 95\% o nível de significância, aceitamos a hipótese nula para $\mathrm{p}>0,05$. Contudo, para aplicar a ANOVA, precisamos nos certificar se os dados encontram-se 
em uma escala intervalar, se a distribuição é normal e se os grupos comparados possuem variância homogênea, pois esses são os critérios para que tal método seja aplicado. A escala intervalar já é garantida pela modelagem Rasch, a homogeneidade da variância foi avaliada pelo Teste de Levene, e a normalidade foi constatada pelo Teste KomogorovSmirnov (K-S). Tanto o Teste de Levene como o K-S tem a hipótese nula de igualdade, como no caso da ANOVA. Os resultados indicaram a homogeneidade das variâncias $(\mathrm{L}=0,038, \mathrm{p}=0,846)$ e a normalidade da distribuição das medidas relativas ao ganho $(\mathrm{K}-\mathrm{S}=0,197, \mathrm{p}=0,59)$.

Para análise do ganho, inicialmente avaliamos o gráfico explicitado na Figura 9.

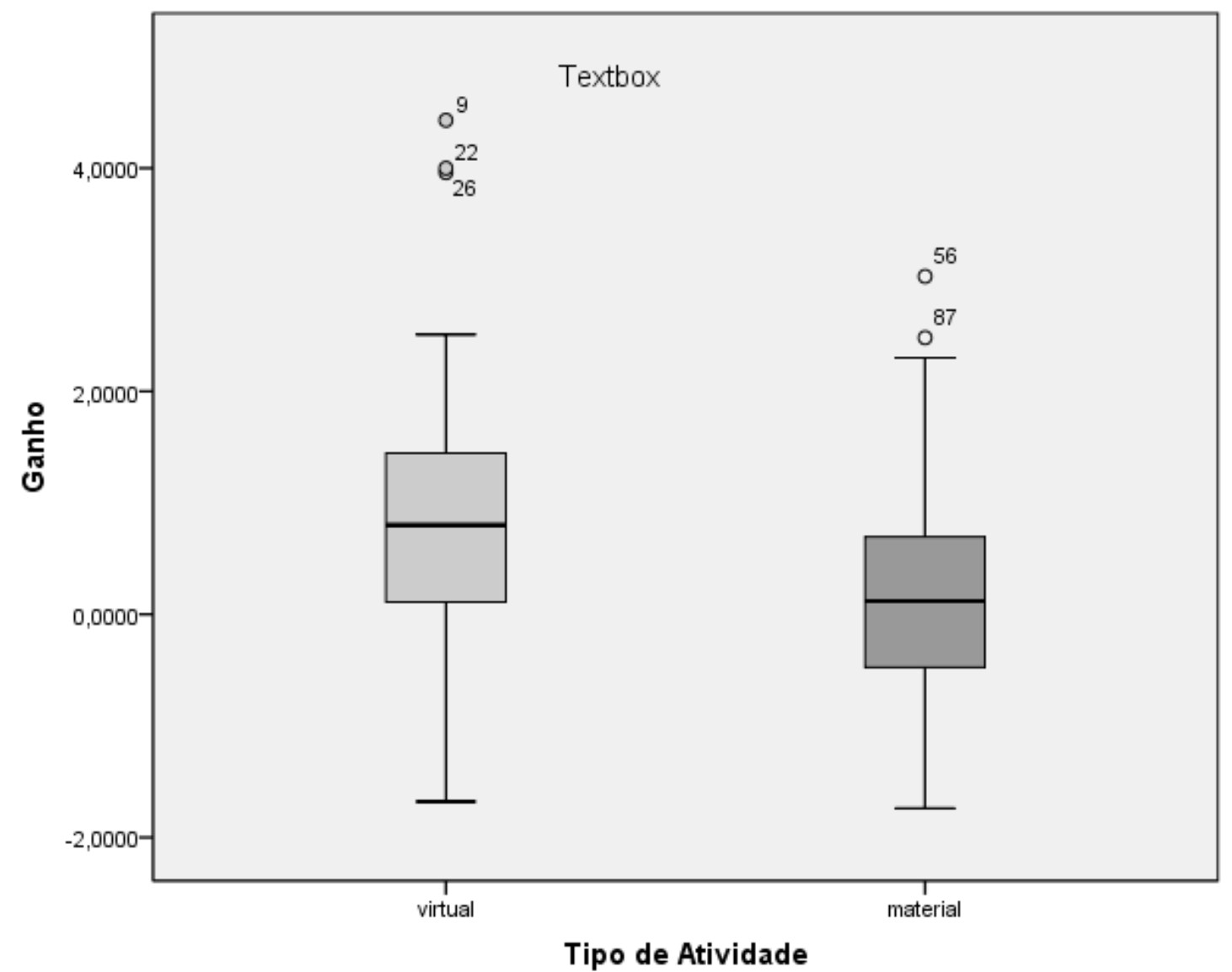

Figura 9. Boxplot (Ganho no entendimento em função do tipo de atividade aplicada)

Fonte: Dados da pesquisa.

Na Figura 9 são plotadas as medidas dos quartis, mediana, amplitude e também os sujeitos outiliers. As caixas (barras) representam os valores centrais da base de dados. A linha inferior representa o primeiro quartil, a linha entre as caixas é a mediana e a linha superior corresponde ao terceiro quartil. É verificada a existência de sujeitos outiliers nos dois ambientes, ou seja, estudantes que tem proficiência muito acima da maioria ou muito abaixo. Em muitos casos, é interessante investigar esses sujeitos a partir do contexto de aplicação. Nesse estudo, contudo, não apresentamos essa análise. 
Pela análise do gráfico verificamos o primeiro indicativo de que houve maior aprendizagem no laboratório em ambiente computacional, observando a linha mediana do bloco que representa o ganho no laboratório em ambiente computacional, que está acima da mediana do bloco que representa o ganho no laboratório em ambiente material. Além disso, através desse gráfico podemos identificar que a aprendizagem no laboratório em ambiente material ocorreu de forma mais homogênea; isso pode ser inferido a partir do quão achatado está o bloco que representa o ganho nesse ambiente. $\mathrm{O}$ achatamento representa a variabilidade das respostas, e, nesse caso, podemos perceber que no laboratório em ambiente computacional essa variabilidade foi maior, uma vez que o bloco que representa o ganho nesse ambiente é menos achatado.

Contudo, somente pela análise do gráfico não temos garantias de que a diferença de ganho nos laboratórios é significativa, podendo ser devido ao acaso ou a variabilidade dos grupos. Para afirmar que houve maior aprendizagem em um dos laboratórios, realizamos o teste de diferença de médias dos ganhos, aplicando assim a ANOVA. Encontramos um ganho médio de 0,871 logits $(S D=1,176)$ para os estudantes que realizaram atividade no laboratório em ambiente computacional e um ganho médio de 0,159 logits $(S D=1,105)$ para aqueles que realizaram a atividade no laboratório em ambiente material. O teste ANOVA está explicitado na Tabela 1.

Tabela 1. Teste ANOVA

\begin{tabular}{ccccc}
\hline \multicolumn{5}{c}{ ANOVA } \\
\hline \multicolumn{5}{c}{ Ganho no entendimento nos laboratórios em ambiente Computacional e Material } \\
\hline & $\begin{array}{c}\text { Soma dos } \\
\text { Quadrados }\end{array}$ & Graus de Liberdade & F & Sig. \\
\hline Entre Grupos & 10,272 & 1 & 7,755 & 0,007 \\
Inter Grupos & 112,590 & 85 & & \\
Total & 122,862 & 86 & & \\
\hline
\end{tabular}

Fonte: Dados da pesquisa.

$\mathrm{O}$ resultado indica que as médias dos grupos não são iguais $(\mathrm{F}=7,755 ; \mathrm{df}=1,85$; $\mathrm{p}=0,007)$ em um nível de significância de $95 \%$. Esse resultado evidencia que houve aprendizagem diferenciada para quem realizou a atividade no laboratório em ambiente computacional (maior ganho no entendimento) em relação a quem realizou a atividade no laboratório em ambiente material (menor ganho no entendimento). Isso significa que, para o conteúdo de Pêndulo Simples em uma atividade cujos elementos materiais correspondentes a suporte de fixação, trena, fio, cronômetro e massas aferidas podem ser manipulados virtualmente, o desempenho em termos de entendimento sobre o conteúdo é maior no ambiente computacional. Interpretamos que, no contexto da atividade investigativa conduzida, a manipulação dos elementos materiais não agregam tantas habilidades fundamentais para o entendimento teórico dos conteúdos de Pêndulo Simples, sendo mais indicado, nesse caso, a atividade computacional. 
Avaliamos a grande dispersão (evidenciada pelo alto desvio padrão e pela presença substancial de outliers) no laboratório em ambiente computacional pelo fato de que nele há uma demanda para manipulação de objetos virtuais, o que requer habilidades distintas do conteúdo. Apesar da familiaridade dos estudantes com ferramentas computacionais, atividades formais nesse ambiente não eram atividades comuns para os participantes do estudo. Dessa forma, uma possível explicação para a dispersão e o maior número de outiliers no laboratório em ambiente computacional pode ser devido ao fato de que os objetos virtuais a serem manipulados demandam ações não usuais nas aulas formais, sendo isso um elemento a mais a ser aprendido ou recontextualizado durante a atividade. Alguns estudantes podem ter perdido o foco do conteúdo aprendendo como lidar com a simulação, o que gerou dispersão na forma como aprenderam. Além disso, manipular objetos concretos não envolve as mesmas ações cognitivas de manipulação de objetos virtuais, e isso certamente interfere na construção do conhecimento em cada tipo de ambiente.

Apesar desse aspecto não ter sido investigado em maior detalhe, ele é um indicativo de que devemos ter cautela para o uso de simulações para o ensino de conteúdos formais, pois eles trazem outros elementos que podem se constituir como obstáculos de aprendizagem dissociados do conteúdo, e que não podemos controlar. Nesse sentido, é necessário pensar em estratégias que minimizem as dificuldades que não dizem respeito ao conteúdo, e isso implica em um planejamento mais detalhado sobre o uso de recursos que demandam habilidades de outra natureza ou domínio de conhecimento. Se não há preocupação nesse aspecto, corremos o risco de utilizar uma abordagem potencialmente válida para otimizar a aprendizagem, mas que não surte $o$ efeito esperado devido a outras limitações que não são as do conteúdo em si.

\section{Estudo 2}

Para além da constatação da aprendizagem nos laboratórios em ambientes computacional e material, outra questão que se faz pertinente nesse tipo de instrução é: Que faceta do conhecimento (conceitual ou procedimental) é mais favorecida em atividades investigativas?

Para responder essa questão, a análise se concentrou em avaliar como os índices de dificuldade dos itens mudaram de um teste para outro, tendo em vista que alguns acessaram a natureza procedimental e outros a natureza conceitual. A Figura 10 mostra exemplos de itens desses dois domínios.

Um item de natureza conceitual diz respeito à definição ou descrição dos fenômenos e conceitos envolvidos no conteúdo de Pêndulo Simples. Já o item de natureza procedimental se refere a um problema ou situação em que o estudante deve aplicar seu conhecimento sobre o conteúdo para resolvê-lo. Consideramos que esses dois aspectos podem estar em graus diferentes de articulação (Amantes, 2005) e que algumas atividades, a depender de como abordam os conteúdos, podem favorecer mais a evolução de uma ou de outra faceta. É importante saber o que cada atividade tem 
como potencial nesse sentido, pois dessa forma ações didáticas mais eficazes podem ser delimitadas para atender a lacunas específicas de aprendizagem.

\begin{tabular}{|l|l|}
\hline Natureza do item & \multicolumn{1}{c|}{ Item } \\
\hline \multirow{5}{*}{ Conceitual } & $\begin{array}{l}\text { Como você explica a aplicação do Teorema da Conservação da Energia Mecânica } \\
\text { ao movimento de um Pêndulo Simples? }\end{array}$ \\
\cline { 2 - 3 } Procedimental & $\begin{array}{l}\text { Defina as condições para que dois Pêndulos Simples tenham o mesmo } \\
\text { período. }\end{array}$ \\
\hline & $\begin{array}{l}\text { Em uma situação de laboratório em que é solicitada a medição da frequência } \\
\text { de um Pêndulo Simples os alunos são informados que não poderão utilizar } \\
\text { equações para a obtenção do resultado. Como você resolveria esta situação? }\end{array}$ \\
\cline { 2 - 2 } & $\begin{array}{l}\text { Em uma aula experimental o professor de Física pede que os alunos calculem } \\
\text { o período de oscilação de um Pêndulo Simples constituído por uma esfera. Em } \\
\text { um determinado momento o professor pede que o fio inextensível do Pêndulo } \\
\text { dobro do comprimento. Em sua opinião o que ocorrerá com o período do novo } \\
\text { pêndulo? }\end{array}$ \\
\hline
\end{tabular}

Figura 10. Exemplos de itens de natureza conceitual e itens de natureza procedimental

Fonte: Dados da pesquisa.

$\mathrm{O}$ indicativo de aprendizagem nesse Estudo 2 foi a mudança dos índices de dificuldade dos itens, ou seja, o quanto eles ficaram mais "fáceis" de uma ocasião para outra (Bond, \& Fox, 2001). Para calcularmos o "ganho" no entendimento fizemos a diferença:

Ganho = Média dificuldade dos itens no Teste $1-$ Média de dificuldade dos itens no Teste 2

Quanto maior essa diferença, maior aprendizagem. A Tabela 2 mostra a média e o desvio padrão dos índices de dificuldade dos itens em cada dimensão, assim como a diferença (ganho).

Tabela 2. Média e o Desvio Padrão dos índices de dificuldade

\begin{tabular}{ccccc}
\hline & \multicolumn{2}{c}{ Procedimental } & \multicolumn{2}{c}{ Conceitual } \\
\hline & Teste1 & Teste2 & Teste1 & Teste2 \\
\hline Média & 0,057143 & $-0,07062$ & $-0,27333$ & 0,252222 \\
\hline DP & 0,733625 & 1,238672 & 1,781939 & 1,302645 \\
\hline \multirow{2}{*}{ Variação } & \multicolumn{2}{c}{$\mathbf{1 2 7 7 6 8}$} & \multicolumn{2}{c}{$\mathbf{0 , 5 2 5 5 5 6}$} \\
& Diminuição da dificuldade em & \multicolumn{2}{c}{ Aumento da dificuldade em } \\
& \multicolumn{2}{c}{0,127768 logits } & \multicolumn{2}{c}{0,525556 logits } \\
\hline
\end{tabular}

Fonte: Dados da pesquisa.

Encontramos valores de média igual a 0,0571 logits $(S D=0,734)$ para o 
entendimento procedimental e média de $-0,273$ logits $(S D=1,782)$ para o entendimento conceitual no Teste 1 . Os dados do Teste 2 forneceram valores de média igual a -0,071 logits $(S D=1,239)$ para o entendimento procedimental e média igual a 0,252 logits (SD $=1,303)$ para o entendimento conceitual.

Enquanto a dificuldade média dos itens de natureza procedimental diminuiu, a dificuldade média dos itens de natureza conceitual aumentou, sendo a variação maior constatada para a média dos últimos. Esse aumento de dificuldade para os itens conceituais pode indicar maior confusão da faceta conceitual em detrimento da aprendizagem procedimental. A perspectiva teórica adotada nesse estudo para interpretar aprendizagem prevê esse tipo de situação no processo, uma vez que a evolução do traço latente é considerada não linear e oscilatória (Fischer, 1980). Nesse sentido, quando avaliamos dois pontos da aprendizagem podemos acessar o traço latente em um momento de desequilíbrio (Piaget, 1976), o que pode aparentar um "retrocesso" no entendimento. Alguns apontam que essa é uma limitação de estudos com design Préteste/ Pos-teste (Coalition for Evidence-Based Policy, 2003). Apesar disso, consideramos que é possível fazer inferências sobre o tipo de conhecimento mais favorecido em atividades dessa natureza. Uma forma de interpretar é justamente levar em consideração que a atividade proporcionou uma evolução da faceta procedimental de maneira mais rápida, pois seus referentes davam subsídio para operar com problemas, ao invés de definições. Dessa forma, a faceta conceitual, menos demandada na atividade, demanda maior tempo para se articular.

Esse resultado evidencia a limitação apontada na literatura para interpretar todas as características da aprendizagem por somente dois pontos, e nos chama a atenção para o estabelecimento de estratégias de avaliação que contemple tanto a natureza oscilatória e dinâmica do processo como a natureza conceitual e procedimental, além da atitudinal não reportada nesse trabalho (Zabala, 1998). Aumentar o número de ondas de medida é uma das ações que podem aumentar a eficiência da avaliação da aprendizagem, pois assim obtemos maior número de pontos para capturar o caráter oscilatório, possibilitando melhores subsídios para interpretá-la.

Em síntese, os resultados do segundo estudo apontam que, no caso do intervalo capturado, obtivemos maior êxito na aprendizagem procedimental. Esse resultado pode ser interpretado a partir de duas perspectivas:

1) o entendimento conceitual requer maior tempo para ser construído em seu maior nível de articulação do que o entendimento procedimental, que diz respeito a aspectos mais pragmáticos.

2) o caráter da atividade potencializa o desenvolvimento de habilidades para resolução de problemas, o que é razoável devido às características das atividades, pois os estudantes deveriam manipular objetos (materiais ou computacionais) a fim de solucionar desafios, empregando seus conhecimentos sobre o conteúdo em ações mais procedimentais.

Em especial, confirmar que atividades em que os estudantes devem manipular 
objetos de aprendizagem (sejam virtuais ou não) para solucionar situações problemáticas reafirma que devemos ter prudência sobre o uso de tal recurso, uma vez que aspectos conceituais não são tão contemplados. Diante desse resultado, devemos avaliar, a partir do contexto de ensino, a adequação de atividades investigativas ao objetivo de aprendizagem, pois ao optar por tal abordagem, estaremos potencializando em maior grau habilidades relacionadas ao saber aplicar o conhecimento para a resolução de problemas. Isso pode ser objetivo do professor em determinado momento de sua ação pedagógica, mas pode não o ser em outro. Nesse sentido, defendemos que entender o papel de cada tipo de abordagem e o que ela promove em sala de aula é fundamental para conduzir um ensino mais eficaz.

\section{Considerações Finais}

Reportamos um estudo cujo objetivo foi investigar a aprendizagem de estudantes do segundo ano do Ensino Médio sobre os conceitos subjacentes ao conteúdo de Pêndulo Simples, quando submetidos a uma intervenção de natureza investigativa em dois diferentes laboratórios de ensino: material e computacional. Além disso, também buscou verificar em que medida aspectos conceituais e procedimentais da aprendizagem são contemplados em tal abordagem.

A pesquisa contou com a participação de 87 estudantes que cursavam o segundo ano do Ensino Integrado de diferentes cursos. Como instrumento de coleta, aplicamos testes que continham algumas questões que solicitavam formulações conceituais e outras interpretações sobre determinadas situações físicas. Como recurso utilizamos uma simulação computacional, capaz de simular um fenômeno em computador e um kit experimental cuja montagem se referiu ao mesmo fenômeno. Utilizamos nesse estudo os dados coletados em dois momentos, antes e após a intervenção em um dos dois ambientes.

Nossos resultados indicam que os conceitos envolvidos no conteúdo de Pêndulo Simples foram mais contemplados na perspectiva procedimental de aprendizagem quando abordados em uma atividade investigativa. Também para esse tipo de atividade, o desempenho foi melhor no laboratório em ambiente computacional do que no laboratório em ambiente material. Apesar de o desenho ter a limitação no que dizem respeito às medidas (apenas duas ondas de coleta de dados), esses resultados indicam a potencialidade do tipo de atividade para o desenvolvimento de habilidades relativas à solução de situações problemáticas em detrimento do entendimento conceitual, e aponta para a alta performance em laboratórios em ambientes computacional, tendo em vista o tipo de atividade desenvolvida.

Não investigamos outros aspectos que trariam maiores detalhes para a interpretação desse resultado, como a questão da motivação, engajamento cognitivo, comportamental e emocional (Fredericks, Blumenfeld, \& Paris, 2004), dentre outros. Mas esse certamente é um bom indicativo de que, para esse conteúdo e em um contexto similar ao da investigação, a atividade investigativa será melhor contemplada ser for 
realizada em laboratório em ambiente computacional. Uma interpretação possível é a de que no experimento utilizado, a manipulação dos elementos virtuais são menos problemáticas do que no caso do kit experimental material, pois nesse último algumas variáveis concretas podem dificultar a realização do desafio, como no caso da oscilação do pêndulo, que no computacional é unidirecional e no material pode ocorrer em outras direções, por exemplo. Certamente esse resultado deve ser melhor compreendido a partir de outros estudos, principalmente porque diz respeito à interpretação de um experimento particular relacionado a um conteúdo específico. Outros resultados podem complementar os obtidos nesseestudo, pois a depender do contexto de ensino, do conteúdo e dos próprios materiais de ensino escolhidos (simulação e kit experimental) diferentes entendimentos podem ser construídos e mobilizados. Dessa forma, consideramos que esses resultados chamam a atenção para o fato de que manuseio dos materiais deve ser levado em consideração quando propomos uma atividade experimental.

Em relação ao caráter procedimental da aprendizagem, afirmamos o pressuposto de que atividades experimentais irão favorecer o entendimento em termos de aplicação do conhecimento. Esse resultado é esperado para um tipo de abordagem que demanda mais habilidades relativas ao manuseio de materiais, ao estabelecimento de relações causais e de implicação, e à interpretação fenomenológica. Ele indica que devemos utilizar esse recurso quando o objetivo de ensino está justamente no desenvolvimento de tais habilidades.

Nossos resultados contribuem com os trabalhos que investigam a articulação dos laboratórios de forma integrada no ensino de Física (Heidemann et al., 2010; Hohenfeld, 2013; Jaakkola, \& Nurmi,2008; Pedrajas, 2017; Zacarias, 2007). Articulamos-nos também com os resultados de Hohenfeld (2013), cujo argumento é o de que os laboratórios de simulação computacionais e convencionais (material) requerem habilidades distintas que estão presentes no nosso cotidiano, contribuem para a superação da visão empíricaindutivista comuns nos laboratórios didáticos e aproxima os estudantes ao trabalho científico, propiciando o desenvolvimento da capacidade de tomar decisões de ordem técnico-científicas.

Acreditamos que nosso estudo também contribui para o delineamento de elementos mais contundentes sobre as potencialidades e limitações da atividade investigativa e dos ambientes de aprendizagem, para que condutas de ensino possam ser melhor direcionadas no intuito de superar obstáculos de aprendizagem. Conteúdos científicos de alto nível de complexidade devem ser ensinados a partir de várias estratégias, a partir de muitas e diferentes abordagens, de maneira a contemplar o pluralismo metodológico (Laburú, Arruda, \& Nardi, 2003) em sala de aula. Contudo, é essencial que sejam elencados os resultados de ensino e aprendizagem alcançados para cada estratégia e/ou método, para que o docente possa, a partir de uma avaliação diagnóstica, optar pela abordagem que mais se adéque aos seus objetivos e ensino e ao perfil de seus estudantes. 


\section{Referências}

Almeida, A., \& Sasseron, L. (2013). As Ideias Balizadoras Necessárias ao Professor ao Planejar e Avaliar a Aplicação de uma Sequência de Ensino Investigativo. In IX Congresso Internacional sobre Investigaçión em Didáctica de Las Ciencias, (pp. 1188-1192). Girona.

Alves Filho, J. (2000). Regras da Transposição Didática Aplicadas ao Laboratório Didático. Caderno Catarinense de Ensino de Física, 17(2), 174-182.

Amantes, A. (2005). O Entendimento de Estudantes do Ensino Médio sobre Sistema de Referência e Movimento Relativo (Dissertação de Mestrado). Belo Horizonte, MG.

Amantes, A. (2009). Contextualização no Ensino de Física: efeitos sobre a evolução do entendimento dos estudantes (Tese de Doutoramento). Belo Horizonte, MG.

Amantes, A., Tavares, M. L., \& Vieira, R. D. (2012). Uma Discussão sobre o Qualitativo e o Quantitativo no Ensino de Ciências. Caderno de Resumos do XIV EPEF, 2012.

Amantes, A., Coelho, G., \& Marinho, R. (2015). A medida nas Pesquisas em Educação: empregando o modelo Rasch para acessar e avaliar traços latentes. Ensaio Pesquisa em Educação em Ciências, 17(3), 657-685, 2015.

Araujo, M. S., \& Abib, M. L. (2003). Atividades Experimentais no Ensino de Física: diferentes enfoque, diferentes finalidades. Revista Brasileira de Ensino de Física, 25(2 ), $176-194$.

Bellucco, A., \& Carvalho, A. (2014). Uma Proposta de Sequência de Ensino Investigativa sobre Quantidade de Movimento, sua Conservação e as Leis de Newton. Caderno Brasileiro de Ensino de Física, 31(01), 30-59.

Biggs, J., \& Collis, K. (1982). Evaluating the Quality of Learning: the solo taxonomy. New York: Academic Press.

Bond, T. G., \& Fox, C. M. (2001). Applying the Rasch Model: Fundamental Measurement in the Human Sciences. Mahwah, N.J.: Erlbaum.

Borges, A. T. (2002). Novos Rumos para o Laboratório Escolar de Ciências. Caderno Catarinense de Física, 19(3), 291-313.

Capecchi, M. C., \& Carvalho, A. M. P. (2000). Argumentação em uma aula de conhecimento físico com crianças na faixa de oito a dez anos. Investigações em Ensino de Ciências, 5(3), 171-189.

Carmo, A. B. (2012). Ensinando Quantidade de Movimento: como conciliar o tempo restrito com as atividades de ensino investigativas na sala de aula? Ciência em tela, 1-9.

Carvalho, A. M. P. (2004). Critérios Estruturantes para o Ensino das Ciências. In: Carvalho, A. M. P. (Org.). Ensino de Ciências: Unindo a Pesquisa e a Prática (pp. 01-17). São Paulo: Pioneira, Thomson Learning. 
Carvalho, A. M. P. (2013). O ensino de Ciências e a proposição de sequências de ensino investigativas. In Carvalho, A.M.P. (org.) Ensino de Ciências por investigação - Condições para implementação em sala de aula. São Paulo: Cengage Learning.

Case, R. (1993). Theories of Lerning and Theories of Development. Educational Psychologist, 28 (3), 219-233. Copyright 1993, Lawrence Associates.

Chisnall, P. (1973). Marketing Research: Analysis and Measurement. McGraw-Hill.

Coalition for Evidence-Based Policy (2003). Identifying and Implementing Educational Practices Supported by Rigorous Evidence: A User Friendly Guide.

Coelho, G. (2011). A evolução do Entendimento dos Estudantes em Eletricidade: um estudo longitudinal (Tese de Doutoramento). Belo Horizonte, MG.

Commons, M. L. (2008). Introduction to the Model of Hierarchical Complexity and its Relationship to Postformal Action. World Futures, 64, 305-320. Copyrigh 2008, Taylor \& Francis Group, LLC ISSN 0260-4027 print / 1556-1844.

Ferreira, P. M. (2009). Habilidades Investigativa no Ensino Fundamentado em Modelagem (Tese de Doutoramento). Belo Horizonte, Minas Gerais, Sudeste: UFMG.

Fischer, K. W. (1980). A Theory of Cognitive Development: the Control and Construction of Hierarchies of Skills. Psychological Review, 87, p. 477-531.

Fischer, K. W. (2008). Dynamic cycles of Cognitive and Brain development. In Battro, A. M., Fischer, K. W. (Ed.). The Educated Brain. Cambridge, U.K. Cambridge University Press, 2008.

Fredricks, J. A., Blumenfeld, P. C., \& Paris, A. H. (2004). School Engagement: Potential of the Concept, State of the Evidence. Review of Educational Research, 74(1), pp. 59-109.

Giordan, M. (1999). O Papel da Experimentação no Ensino de Ciências. Química Nova na Escola, 10, 43-49, São Paulo.

Golafshani, N. (2003). Understanding reliability and validity in qualitative research. The Qualitative Report, Canadá, 8(4), 597-607.

Gomes, A., Borges, A., \& Justi, R. (2008). Processos e Conhecimentos Envolvidos na Realização de Atividades Práticas: revisão da literatura e implicações para a pesquisa. (Processes and forms of knowledge involved in practical activities: a review of the literature and implications for research). Investigações em Ensino de Ciências 13(2), p. 187-207.

Guttman, L. (1944). A Basis for Scaling Qualitative Data. n. 9, p. 139-150. American Sociological Review.

Heidemann, J. C., Andrade, L. R. B., Stähelin, D., Prezzi, H. A., Valentini, G., \& Bertoldo J. G. et al. (2010). Variabilidade em Acessos do Banco Ativo de Germoplasma de feijão do CaV/UDESC. In Congresso de Iniciação Científica de Pós-Graduação, Florianópolis. Anais eletrônicos. Florianópolis: UNDESC, 2010. 
Hestenes, D., \& Halloun, I. (1995). Interpreting the force concept inventory: A response to March 1995 critique by Huffman and Heller, Phys. Teach. 33, 502, 1995.

Hohenfeld, D. (2013). A Natureza Quântica da Luz nos Laboratórios Didáticos Convencionais e Computacionais no Ensino Médio (Tese de Doutoramento). Salvador, Bahia, Brasil.

Jaakkola, T., \& Nurmi, S. (2008). Fostering elementary school students understanding of simple electricity by combining simulation and laboratory activities. Journal of Computer Assisted Learning, 24(4), p. 271-283. 2008.

Kincheloe, J. (2001). Describing the bricolage: Conceptualizing a new rigor in qualitative research. Qualitative Inquiry, 7(6), 679-692, 2001.

Laburú, C. E., Arruda, S. M., \& Nardi, R. (2003). Por um Pluralismo Metodológico para o Ensino de Ciências. Ciência e Educação (UNESP), 9(2), p. 247-260, 2003, São Paulo.

Lévy, P. (1993). As tecnologias da Inteligência. Tradução de Carlos Irineu da Costa. Rio de Janeiro: Ed. 34, 1993.

Lima, S. C., \& Takahashi, E. K. (2013). Construção de conceitos de eletricidade nos anos iniciais do ensino fundamental com uso de experimentação virtual. Revista Brasileira de Ensino de Física, 35(2), 2013.

Linacre, J. M., \& Wright, B. D. (1991). WINSTEPS - Rasch-Model computer programs. Chicago: MESA Press.

Linacre, J. M. (2014). A user's guide to WINSTEPS and ministep Rasch model computer programs: Program manual 3.81. Chicago: Winsteps.

Medeiros, A., \& Medeiros, C. F. (2002). Possibilidades e Limitações das Simulações Computacionais no Ensino da Física. Revista Brasileira de Ensino de Física, 24(2), p. $77-86$.

Millar, R. (2010). Analysing Pratical Science Activities to Assess and Improve their Effectiveness.

Muller, M. G., Araujo, I. S., Veit, E. A., \& Schell, J. (2017). Uma revisão da literatura acerca da implementação da metodologia interativa de ensino Peer Instruction (1991 a 2015). Revista Brasileira de Ensino Física. São Paulo, 39(3), e3403. Epub Mar 13, 2017. http://doi.org/10.1590/1806-9126-rbef-2017-0012

Oliveira, J. (2010). Contribuições e Abordagens das Atividades Experimentais no Ensino de Ciências: reunindo elementos para a prática docente. 12(1) jan/jun. Acta Scientiae, p. 139-153.

Parasuraman, A. (1991). Marketing Research. New York: Addison-Wesley Publishing Co. 
Pereira, M. V., \& Moreira, M. C. A. (2017). Atividades prático-experimentais no ensino de física. Caderno Brasileiro de Ensino de Física, 34(1).

Pedrajas, A. P. (2017). El uso de Simulationes Interactivas para Comprender el Modelo de Corriente Elétrica. X Congresso International sobre Investigación em Didáctica de las Ciencias. Sevilla 5-8 de septiembre de 2017 ISSN (DIGITAL): 2174-6486.

Piaget, J. (1976). A equilibração das Estruturas Cognitivas. Rio de Janeiro: Zahar Editores. Rasch, H. (1964). Z. ärztL Fortbild. (Lena), 58, 335.

Regebe, F. A., \& Amantes, A. (2013). Habilidades X Entendimento de Conceitos Abstratos Relacionados ao Raciocínio Lógico: uma análise preliminar. In IX Encontro Nacional de Pesquisa em Ensino de Ciências, 2013, Águas de Lindóia. Anais do IX EPEF, 2013.

Sasseron, L. H., \& Carvalho, A. M. (2011). Uma Análise dos Referenciais Teóricos sobre a Estrutura do Argumento para Estudos de Argumentação no Ensino de Ciências. Uma análise dos referenciais teóricos sobre a estrutura do Ensaio. Pesquisa em Educação em Ciências, 13(3), p. 243-262.

Shaffer, D. W., Serlin, R. C. (2004). What Good are Statistics That don't Generalize? Educational Researcher, University of Wisconsin, Madison, 9(33), p. 14-25, Dec. 2004.

Snetinová, M., Kácovský, P., \& Machalická, J. (2018). Hands-On Experiments in the Interactive Physics Laboratory: Students' Intrinsic Motivation and Understanding. Center for Educational Policy Studies Journal, 8(1), p. 55-75.

Suart, R., \& Marcondes, M. (2009). A Manifestação de Habilidades Cognitivas em Atividades Experimentais Investigativas no Ensino Médio de Química. Ciência \& Cognição, p. 50-74.

Tamir, P. (1991). Pratical work at school: na analysis of current pratice. In: B. Woolnough (Ed). Pratical Science. Milton Keynes: Open University Press.

Vasconcelos, F. H. L., Carvalho, R. O., Romeu, M. C., \& Neto, H. B. (2005). A Utilização de Software Educativo Aplicado ao Ensino de Física com o Uso da Modelagem. XVI Simpósio Nacional de Ensino de Física, 2005.

Velasco, J. J., \& Buteler, L. M. (2017). Simulaciones Computacionales em la Enseñanza de la Física: uma revisión crítica de los últimos años. Ensenanza de Las Ciencias. ISSN: 0212-4521, 2017.

Vieira, R. D. (2001). Discurso em salas de aula de ciências: Uma estrutura de análise baseada na teoria da atividade, sociolinguística e linguística textual (Tese de Doutoramento). Faculdade de Educação, UFMG, 2011.

Wright, B. D. (1998). Where do dimensions come from? Popular Measurement, University of Chicago-USA, (1)1, p. 32, 1998. 
Zabala, A. (1998). A Prática educativa: como ensinar. Porto Alegre: ArtMed.

Zômpero, A. F., Passos, A. Q., \& Carvalho, L. M. (2012). A Docência e as Atividades de Experimentação no Ensino de Ciências nas Séries Iniciais do Ensino Fundamental. Experiências em Ensino de Física, 7(1), p. 43-54.

Silvia Carla Cerqueira Porto

${ }^{\circledR}$ https://orcid.org/0000-0002-3874-6110 Instituto Federal de Educação da Bahia Feira de Santana, Bahia, Brasil silviaporto@ifba.edu.br

Amanda Amantes

(10 https://orcid.org/0000-0003-1678-9870 Universidade Federal da Bahia

Faculdade de Educação

Salvador, Bahia, Brasil amandaamantes@gmail.com

\section{Dielson Pereira Hohenfeld}

(D) https://orcid.org/0000-0002-1242-7322 Instituto Federal de Educação da Bahia Salvador, Bahia, Brasil dielson.dph@gmail.com

Submetido em 29 de julho de 2019 Aceito em 18 de novembro de 2019 Publicado em 06 de janeiro de 2020 